\title{
La decoración excisa como indicador de procesos de interacción e intercambio durante el Bronce Final en el valle medio del Ebro. Reflexiones a partir de nuevos hallazgos y dataciones absolutas*
}

\author{
Excised decoration as an indicator of interaction and exchange processes in the Late \\ Bronze Age in the middle Ebro valley. An approach based on new discoveries and \\ radiocarbon dates
}

Paloma Aranda-Contamina ${ }^{\mathrm{a}}$ y José María Rodanés Vicente ${ }^{\mathrm{a}}$

\section{RESUMEN}

En este artículo se estudia la cerámica excisa como un indicador de los procesos de interacción e intercambio en el valle medio del Ebro. A partir de una breve historiografía abordamos el estado de la cuestión de las investigaciones sobre la cerámica excisa, tema que desde finales de la década de 1980 apenas ha sido tratado en este territorio. La incorporación de nuevos yacimientos y, en especial, las series de dataciones absolutas de los fondos de cabaña de El Sequero (Arrúbal), del yacimiento de Partelapeña (El Redal), ambos en tierras riojanas, y del poblado de El Morredón (Fréscano, Zaragoza) en el valle del Huecha son el punto de partida de una serie de reflexiones sobre los mecanismos sociales que propiciaron la aparición y distribución espacial de esta alfarería. La aplicación de estadística bayesiana al repertorio de fechas radiocarbónicas permite presentar un marco cronológico para las primeras manifestaciones de cerámica excisa que coinciden mayoritariamente con la presencia de Cogotas I, la posterior incorporación del repertorio decorativo a formas y tipos habituales en el Bronce Final, Campos de Urnas, y su progresiva desaparición durante la Primera Edad del Hierro. excised pottery in the Ebro valley, a subject that has not been researched since the eighties. The discovery of new archaeological sites and its radiocarbon dates from $\mathrm{El} \mathrm{Se-}$ quero (Arrúbal), Partelapeña (El Redal), both in La Rioja region, and El Morredón (Fréscano, Zaragoza), in Huecha valley, are the starting point for some hypotheses about the origin and spatial distribution of the excised pottery in the middle Ebro valley. Bayesian statistics has been applied to analyze new radiocarbon dates with the aim of defining a chronological framework. Excised pottery in the middle Ebro valley started with the Cogotas I Culture, afterwards it was adapted to the common typology of the Urnfield Culture during Late Bronze Age, and gradually disappeared during the Early Iron Age.

Palabras clave: Cerámica excisa; Cronología; Estadística bayesiana; Cogotas I; Campos de Urnas; Bronce Final; Primera Edad del Hierro; valle medio del Ebro; Península ibérica.

Key words: Excised pottery; Chronology; Bayesian statistic; Cogotas I; Urnfield Culture; Late Bronze Age; Early Iron Age; middle Ebro valley; Iberian peninsula.

\section{INTRODUCCIÓN}

In this paper, we consider excised (chip-carved) pottery as an indicator of interaction and exchange processes in the middle Ebro valley. We begin with the state of the art about
El origen e implantación de la cerámica con decoración excisa en la península ibérica ha sido objeto de

* Este trabajo se enmarca en el proyecto HAR2015-65620-P: "Paisaje y Sociedad: el valle medio del Ebro entre el 6000 y el 500 cal ANE" (MINECO/FEDER). P. Aranda disfruta de un contrato predoctoral financiado por Diputación General de Aragón, cofinanciado con Fondo Social Europeo (2014).

a Área de Prehistoria, Dpto. Ciencias de la Antigüedad. Universidad de Zaragoza. C/ Pedro Cerbuna 12. 50009 Zaragoza. Correos e.: paranda@ unizar.es https://orcid.org/0000-0002-9278-1355; jrodanes@unizar.es https://orcid.org/0000-0001-9644-4252

Recibido 20-IV-2018; aceptado 24-VII-2018.

Copyright: (C) 2019 CSIC. Este es un artículo de acceso abierto distribuido bajo los términos de la licencia de uso y distribución "Creative Commons Reconocimiento 4.0 Internacional" (CC BY 4.0). 
un buen número de ensayos a lo largo del siglo XX. Habitualmente han ido de la mano de los dedicados al Bronce Final y Primera Edad del Hierro del valle del Ebro y de la Meseta, territorios en los que desde las primeras décadas se fueron detectando producciones alfareras con esta técnica ornamental. Sin pretensiones de exhaustividad y siendo conscientes del evidente predominio de las explicaciones de corte historicista, abordamos una sucinta historia de las investigaciones con el fin de plasmar diferentes interpretaciones que, aún dentro de un mismo paradigma, son necesarias para contar con un diagnóstico preciso a día de hoy.

\subsection{Una breve historiografía}

A comienzos del siglo XX los primeros hallazgos de cerámica excisa se localizaron en tres zonas: el valle del Ebro con el poblado bajoaragonés del Roquizal del Rullo, el castro de Cogotas en la meseta norte (Cabré 1929, 1930) y los yacimientos de los alrededores de Madrid (Pérez de Barradas 1934). La explicación del arqueólogo aragonés Cabré contemplaba una posible producción indígena enraizada en la tradición campaniforme, mientras el erudito madrileño Pérez de Barradas defendía una supuesta relación con las culturas centroeuropeas de la Edad del Bronce. Sus propuestas siguen siendo objeto de debate.

La proliferación de hallazgos propició la primera síntesis a cargo de M. Almagro Basch (1939). Su teoría por la personalidad de su autor, las circunstancias político sociales y la ausencia de nuevas investigaciones se mantendrá vigente durante casi cuarenta años. La cerámica excisa tendría un único origen en la Cultura de los Túmulos del sur de Alemania y llegaría a la península ibérica a través de los Pirineos de la mano de gentes indoeuropeas con una cultura propia de Campos de Urnas. El origen inmediato era ultrapirenaico, pero la génesis de la técnica decorativa se relacionaba con el vaso campaniforme peninsular que, en su expansión fuera de nuestras fronteras, influiría en la Cultura de los Túmulos (Almagro Basch 1939: 141-142).

El valle del Ebro, por su estratégica situación, se convirtió en necesario protagonista de estas teorías. Conceptos como "indoeuropeización" o "celtización", a partir de la presencia de elementos hallstátticos o de Campos de Urnas centroeuropeos, fueron utilizados de manera habitual desde el final de la Guerra Civil. La visión europeísta era unánimemente aceptada (Bosch Gimpera 1932, 1945; Martínez Santaolalla 1946; Almagro Basch 1952; Maluquer 1954, 1958; Beltrán 1956). Todas estas referencias y otras muchas más generales aparecen reseñadas de manera exhaustiva en "La Indoeuropeización del valle del Ebro" de Beltrán (1960). Aquí se refuerza la procedencia centroeuropea de la cerámica excisa para los conjuntos del valle, y en especial para los bajoaragoneses, donde se producen "modos decorativos de una regularidad asombrosa y copiados servilmente" de modelos de Hallstatt A y B, e incluso de temas del Bronce Final (Beltrán 1960: 112).

El trabajo de Molina y Arteaga (1976) cambiará la dinámica de las investigaciones. La técnica de la excisión se vincula con la cerámica campaniforme, estilo Ciempozuelos, cuya influencia en la génesis de Cogotas I será determinante. A la vez se establece una diferencia nítida con la alfarería del valle del Ebro cuya vinculación con las culturas transpirenaicas se sigue manteniendo (Molina y Arteaga 1976: 176).

M. Almagro Gorbea (1977: 114) no se posiciona a favor de un origen ni en el campaniforme, ni en las culturas centroeuropeas del Hallstatt C y D. Reinterpreta la procedencia continental a través del suroeste de Francia, donde regiones como Aquitania actuarían como catalizador de las primeras importaciones desde la Cultura de los Túmulos. Es un pensamiento muy cercano al expuesto por Coffyn (1979: 645) por esas fechas, partiendo de la definición del Grupo de Duffaits (Gómez de Soto 1973; Gómez de Soto et al. 1988).

Muy interesantes y de calculada ambigüedad son las reflexiones de G. Delibes (1978), plasmadas en su discurso a propósito del enterramiento de San Román de la Hornija. A la pregunta de si la excisa de Cogotas I es autóctona o importada opta por una respuesta no exenta de cautela y destaca que "todos los grupos europeos con excisión de la Edad del Bronce tienen una tradición cerámica de incrustación y reúnen condiciones para poder haber sido originarios o creadores de esta técnica" (Delibes 1978: 241). A la vez asume que Cogotas I es una cultura indígena con una cerámica a la moda de otros grupos de pastores de la época (Delibes 1978: 242).

Los sucesivos trabajos de G. Ruiz Zapatero (1980, $\left.1981,1985^{1}\right)$ son referentes en la historiografía del valle del Ebro ya que recogen y analizan de manera exhaustiva todos los hallazgos. Su visión coincide con la de Molina y Arteaga (1976).

En paralelo se gesta una visión radicalmente distinta cuyo exponente son los artículos sobre el Bronce Final y la Edad del Hierro en el valle del Ebro publicados por M. Pellicer (1984a, 1984b, 1985). Rebate la procedencia suprapirenaica, renana o francesa, optando definitivamente por un origen peninsular en el horizonte Cogotas I, inspiración tanto de los vasos del alto y medio Ebro como del Bajo Aragón (Pellicer 1985: 356). Esta misma idea, afirmada de modo menos

\footnotetext{
1 Ruiz Zapatero, G. 1985: Los Campos de Urnas del Noreste de la Península Ibérica. Tesis doctoral inédita. Universidad Complutense. Madrid.
} 
contundente, subyace en la monografía dedicada a la cerámica excisa del alto y medio Ebro, último ensayo dedicado a este tema y de cuya redacción se cumplen ahora treinta años (Álvarez y Pérez Arrondo 1987: 117).

El valle medio del Ebro permanecerá anclado en las investigaciones de la década de 1980. La aceptación de las tesis de Pellicer es habitual en la mayoría de las referencias, asumiendo la procedencia interior, desde la Meseta al valle, y con una supuesta mayor antigüedad en el alto y medio Ebro respecto a las tierras orientales (Ruiz Zapatero 1995: 27-28, 2010: 95).

Si queremos avanzar en el conocimiento es preciso cambiar determinadas dinámicas y modificar el discurso. Sirvan como ejemplo recientes ensayos sobre Cogotas I en la Meseta referidos tanto a la cerámica como al declinar de la propia cultura y su evolución a la Edad del Hierro (Blanco 2010, 2012, 2015, 2018). Pero ante todo urge paliar el notorio descenso de la producción científica sobre la Edad del Bronce que se aprecia en algunas comunidades autónomas. Es llamativa la ausencia de investigaciones desde la década de 1980 en La Rioja (Rodanés et al. 2016), realidad muy distinta a la de la limítrofe Comunidad de Navarra, donde se cuenta con un nutrido repertorio de yacimientos y hallazgos (Castiella 1977, 1995; Armendáriz 2008; Llanos et al. 2009). En Aragón, salvo raras excepciones, desde los trabajos de Maya $(1981,1992-$ 1993) y Ruiz Zapatero ${ }^{2}$, el silencio en la investigación es clamoroso (Aranda-Contamina y Rodanés 2016).

A pesar del negativo diagnóstico, lo avanzado en el conocimiento del II milenio y comienzos del I a. C. permite centrar el problema de la cerámica excisa, en especial en el denominado Bronce Tardío. La situación aún así es compleja. El inevitable fracaso en el afán por describir realidades arqueológicas homogéneas ha restado visibilidad a esta cerámica. Las investigaciones muestran un mosaico con límites difusos que, por el momento, intentamos describir, datar e interrelacionar en la medida de lo posible (Sesma y García 1994; Rodanés 1995; Rodanés y Sopena 1998; Picazo 2005).

En Arqueología, un fenómeno se hace visible cuando se reúnen una serie de hallazgos con ciertas características comunes que se intenta explicar mediante diferentes paradigmas interpretativos, no necesariamente excluyentes. En nuestro caso estudiamos la cerámica excisa como un rasgo en el interior de un subsistema tecnológico, económico, social o simbólico. El que no pretendamos tratar el sistema cultural en su totalidad no excluye que valoremos los pequeños o grandes cambios en un simple rasgo como una alerta de las variaciones que pueden modificar comporta-

\footnotetext{
2 Véase n. 1
}

mientos del sistema general. Habitualmente, según la teoría clásica, la zona con mayor antigüedad y densidad de hallazgos es la de invención, fábrica y posterior expansión a otros territorios. Por ello, es de crucial importancia situar en el espacio los hallazgos y definir los contextos donde se producen por primera vez. Igualmente, debemos ser conscientes de que los límites, geográficos o políticos, que imponemos en nuestros ensayos no se corresponden con realidades arqueológicas. Somos partidarios y damos gran importancia a los estudios a escala local, con planteamientos muy cercanos a la denominada microhistoria (Rodanés y Picazo 2005: 7-9). Esto en modo alguno es un inconveniente para ampliar la escala y determinar los procesos en otras zonas cuyas poblaciones han podido interrelacionarse, excepto que consideremos, y no es el caso, que el fenómeno investigado se genera en el territorio estudiado.

La situación estratégica del espacio que estamos tratando, indudablemente, debe tenerse en cuenta, ya que factores como la permeabilidad, las rutas y vías de comunicación natural son importantes para valorar las posibilidades de relación, interacción o intercambios. Por ello creemos necesario apreciar la realidad arqueológica de territorios cercanos cuyas relaciones a lo largo de la Prehistoria están perfectamente documentadas.

\subsubsection{Sobre Cogotas I}

En estos últimos treinta años, las investigaciones sobre la Edad del Bronce en la Meseta han experimentado un espectacular desarrollo. De territorio prácticamente desconocido y marginal frente a las culturas de la costa mediterránea ha pasado a ser uno de los mejor conocidos con solventes y continuados trabajos en el ámbito de Cogotas I (Delibes 1978, 1983; Jimeno 1984; Delibes y Fernández Miranda 1986-1987; Delibes et al. 1995; Fernández Posse 1998; Abarquero 2005; Rodríguez Marcos 2007; Blasco 2012; Rodríguez Marcos y Fernández Manzano 2012). Diferentes revisiones historiográficas así lo confirman (Fernández Posse 1998: 11-24; Abarquero 2005: 11-28; Blanco 2012: 18-21).

Como sucede en otros ámbitos espacio-temporales, el desarrollo de la alfarería se ha tenido en cuenta como elemento primordial para construir los primeros esquemas y periodizaciones (Castro-Martínez et al. 1995). La cerámica con decoración excisa, incisa y de boquique han sido objeto de especial atención. Se admite que la primera técnica se incorpora al repertorio decorativo en momentos plenos y avanzados de Cogotas I (Rodríguez Marcos 2007: 436-437). En cronologías absolutas podríamos hablar de su inicio en tor-

Trab. Prehist., 76, N. ${ }^{\circ}$ 1, enero-junio 2019, pp. 84-101, ISSN: 0082-5638

https://doi.org/10.3989/tp.2019.12227 
no al 1500/1450 cal AC y el declinar de la misma sobre 950 cal AC (Abarquero 2005: 65).

Recientes descubrimientos en varios yacimientos, sin embargo, han puesto de relieve nuevamente los recipientes con formas y decoraciones de estilo Duffaits, analizándose los contextos de manera pormenorizada. No se trata de una explicación genérica como las citadas (Almagro Gorbea 1977; Coffyn 1979), sino de reflexiones que marcan una nueva tendencia y obligan a mantener abiertas otras posibilidades de interpretación. El artículo de referencia (Delibes et al. 2000) combina un minucioso estudio de la taza carenada de la cueva del Asno, un buen estado de la cuestión y la pormenorizada descripción de ejemplos que se alejan de los patrones decorativos habituales en Cogotas I. A la vez explora interesantes mecanismos o hipótesis sobre su presencia en tierras hispanas que se distancian de los clásicos argumentos historicistas, sentando las bases de posteriores explicaciones. Por cercanía a nuestro ámbito de estudio destacaremos las piezas de Castilviejo de Yuba (Soria) y el cuenco, mejor que tapadera, de Urrea de Jalón (Delibes et al. 2000: 106-115), así como los recipientes o fragmentos de Cueva Maja (Samaniego et al. 2001: Fig. 91, 58), El Mirador (Moral del Hoyo et al. 2003-2004) y, ya en el valle del Ebro, el reciente hallazgo de Marijuan VI en Navarra (Sesma et al. 2009: 69-70), y el más dudoso de la Loma Grasa en el Bajo Aragón (Álvarez Gracia 1990: 100).

Esta realidad comienza a ser tenida en cuenta en recientes publicaciones (Rodríguez Marcos 2007: 371 372; Blanco 2015: 45, 2018: 26) y de nuevo, bajo otras perspectivas, debe examinarse el proceso dada la antigüedad de los contextos posibles donde se documentan las piezas. Ello supondría replantearse el origen o el proceso de adopción de la técnica.

\subsubsection{Una mirada al norte de los Pirineos}

Los ensayos de Millotte en la senda de clásicos trabajos que se remontan a finales del siglo XIX marcan las tendencias en la investigación que hasta la década de 1970 destacarán las relaciones y la importancia de la Cultura de los Túmulos nordalpinos y en especial el Grupo de Hagueneau para explicar el desarrollo del Bronce Medio y Final. En el caso de la excisión defenderá las grandes semejanzas entre Alsacia y los grupos de Alemania del Sur, sin pronunciarse claramente sobre su origen, pero aceptando que sería un núcleo que irradiaría su influencia en todas las direcciones (Millotte 1961: 216).

Los matices, nuevas investigaciones y propuestas ocuparán las décadas de 1970 y 1980. Señalaremos dos acontecimientos importantes: la definición por par- te de Gómez de Soto $(1973,1995)$ de la Cultura de Duffaits y las ponencias y comunicaciones del Congreso de Estrasburgo de 1988. En ellas se aborda el estado de la cuestión sobre la "Dinámica del Bronce Medio en Europa occidental" (Mordant 1989), destacando la diversidad cultural, a la vez que se replantea la unidad de la técnica y la dependencia del Grupo de Haguenaeau, con una clara plasmación cartográfica de la repartición de los diferentes tipos de cerámica excisa en el país vecino (Piningre y Plouin 1989, en especial tipo 23).

Los trabajos de Gómez de Soto van a tener gran repercusión en las teorías antes señaladas (Almagro Gorbea 1977; Coffyn 1979; Ruiz Zapatero 1980, $1985^{3}$ ). Si en un principio el autor francés admite que ciertas formas tienen sus raíces en el Bronce Antiguo de la zona y las decoraciones excisas revelan un influjo oriental (Gómez de Soto 1995: 140-142), con el paso del tiempo las irá desligando de las fuertes influencias de la Cultura de los Túmulos y señalando la posibilidad de fenómenos de convergencia, sugerirá una poligenia o un modelo multipolar para los diferentes tipos de las regiones de Francia. La cronología de la cerámica en cada una de ellas es tan antigua como la de los primeros ejemplares de la Cultura de los Túmulos, por lo que se podría argumentar un origen independiente y una evolución paralela (Gómez de Soto 2010, 2013).

El denominado grupo de Saint Véredème (Arnal y Riquet 1961), distribuido por gran parte de Languedoc oriental, ha sido igualmente utilizado como argumento a favor de la existencia de cerámica excisa en el valle del Ebro. En este caso las afinidades formales (tipológicas y decorativas) son menores. Solo en la taza bien descrita y explicada de Serinyá serían patentes (Arnal y Riquet 1961: 22; Molina y Arteaga 1976: 197). Desde las primeras investigaciones se aprecia una clara tendencia a desligar su génesis de las corrientes centroeuropeas. Se descarta la influencia de la cultura tumular germánica, centrándose en la evolución local a partir de las decoraciones de la cerámica de Ferriéres y del campaniforme local, donde llegan a identificar auténticas excisiones configurando zig-zag y dientes de lobo, estando presentes todos los motivos que luego aparecerán en Saint Véredème. Definitivamente, rechazan las posibles influencias externas, salvo la de la Cultura de Polada (Arnal y Riquet 1961: 18-23). Proponen una cronología antigua que más tarde Roudil (1972) hará coincidir con el Bronce Final I y comienzos del II, prolongando su influencia, aunque con notables diferencias en técnica y estilo, en las decoraciones excisas de la Primera Edad del Hierro

\footnotetext{
3 Véase n. 1.
}

Trab. Prehist., 76, N. ${ }^{\circ}$ 1, enero-junio 2019, pp. 84-101, ISSN: 0082-5638 https://doi.org/10.3989/tp.2019.12227 
languedociense en la que tampoco se aprecian influencias de las culturas centroeuropeas (Dedet 1980: 43).

\section{YACIMIENTOS CON CERÁMICA EXCISA EN EL VALLE MEDIO DEL EBRO}

Contamos con buenos repertorios que progresivamente se han ido actualizando tanto de los hallazgos del valle del Ebro que incumben a Cogotas I como a los relacionados con el Bronce Final y Primera Edad del Hierro. Los trabajos iniciales, mas generales, sobre el primer grupo son los de Molina y Arteaga (1976), Ruiz Zapatero (1981, 19854) y Hernández Vera (1983). Los más recientes de Narvarte (2001) y Abarquero $(2005,2012)$ recogen y cartografían las referencias pormenorizadas del alto y medio Ebro, Jalón-Alto Huerva e interior de Aragón, junto al análisis de formas y motivos decorativos (Abarquero 2005: 112-141). Se les añaden el igualmente novedoso de Navarra (Sesma et al. 2009) o los escasos fragmentos inéditos de Peña Amarilla (Urrea de Jalón).

Sobre el segundo grupo, más propio del Bronce Final, no hay grandes novedades respecto a las obras ya señaladas. Navarra es la comunidad con las actualizaciones más recientes (Armendáriz 2008; Llanos et al. 2009). En el resto del territorio los hallazgos aislados acrecientan el repertorio: en la Rioja se deben mayoritariamente a prospecciones superficiales (Pascual Mayoral y Pascual González 1984; Pascual González 2000; Antoñanzas e Iguacel 2011: 45-50), mientras en Aragón, todavía permanecen inéditos: Carracierzo (Bisimbre), El Quez (Alberite de San Juan), Burrén y Burrena (Fréscano), El Convento (Mallen), El Calvario (Calatorao) o los fragmentos del nivel inferior de Cabezo Morrudo (Rodén) ${ }^{5}$ (Fig. 1). Dada la precariedad de las investigaciones, siguen siendo válidas la cartografía, el tratamiento de motivos y las descripciones literarias de Pellicer (1985), las tablas de Álvarez y Pérez Arrondo (1987) y Abarquero (2005), con interesantes diagramas evolutivos en las décadas siguientes (Ruiz Zapatero 1995: 28). Los nuevos vasos decorados anteriormente citados no aportan tipos o decoraciones inéditas.

Hemos intentado paliar la ausencia o escasez de dataciones absolutas, una de las carencias más significativas, combinando la revisión de las dataciones C14 de dos yacimientos ya conocidos y un tercero recientemente publicado con su significativa colección de

\footnotetext{
${ }^{4}$ Véase n. 1.

5 Todas estas novedades están siendo objeto de estudios pormenorizados. Agradecemos a Isidro Aguilera, Director del Museo de Zaragoza, el acceso a los mismos.
}

cerámicas excisas procedentes de contextos ajenos a Cogotas I.

\subsection{Yacimientos con cerámica excisa y nuevas dataciones absolutas}

\subsubsection{Partelapeña (El Redal, La Rioja)}

La publicación de Álvarez y Pérez Arrondo (1987), la más significativa hasta la fecha, recoge el descubrimiento, excavación y exposición de resultados en este poblado desde 1930. En la tesis de P. Álvarez ${ }^{6}$, se estudian antiguos materiales y los aparecidos en las nuevas campañas de excavación.

Las dataciones correspondientes al final de la Edad del Bronce y Primera Edad del Hierro que presentamos son deudoras de la metodología y resultados de las investigaciones antes comentadas (Pérez Arrondo 1983). En este trabajo mantendremos las denominaciones de las fases propuestas en la monografía sobre la cerámica con decoración excisa (Álvarez y Pérez Arrondo 1987: 33-35), que no se modificaron en los estudios posteriores, centrándonos en las que poseen dataciones absolutas y, en especial, en las obtenidas recientemente?

Nivel V. Coincide con un extenso poblado celtibérico. Las dataciones de 1979 extraídas de cereal carbonizado identificarían momentos puntuales de esta ocupación (CSIC-622 [2320 \pm 50 BP] y CSIC-623 $[2260 \pm 50 \mathrm{BP}])$.

Nivel IV. Más impreciso, documentado únicamente en el corte V, se caracterizaba por la presencia de los pequeños vasos globulares de cuello cilíndrico característicos de la Primera Edad del Hierro (Álvarez y Pérez Arrondo 1987: 33). Una datación (Beta-325724, $2520 \pm 40$ BP) coincide exactamente con una de las proporcionadas por una serie de carbones del primer poblado de la Edad del Hierro del Cabezo de la Cruz de la Muela (Zaragoza) (Picazo y Rodanés 2009: 78).

Nivel III, estratos b1-b2 y c2 de 1979, coincide con la ocupación más importante e intensa. De él proceden los característicos materiales cerámicos con decoración excisa (Álvarez y Pérez Arrondo 1987: 3335). Se conocía una datación (CSIC-621, $2630 \pm 50$ BP) que sería coincidente con una segunda recuperada en el corte V (Beta-325725, $2670 \pm 40$ BP). A esta hay que añadir la nueva procedente del mismo nivel, PART III (Beta-325723, $2570 \pm 30$ BP).

\footnotetext{
6 Álvarez Clavijo, P. 1993: El yacimiento arqueológico de Partelapeña (El Redal, La Rioja) en el contexto de la Prehistoria del Valle del Ebro. Tesis doctoral inédita. Universidad de Zaragoza.

${ }^{7}$ Las muestras de fauna han sido proporcionadas por P. Álvarez al que agradecemos la selección de las mismas.
} 


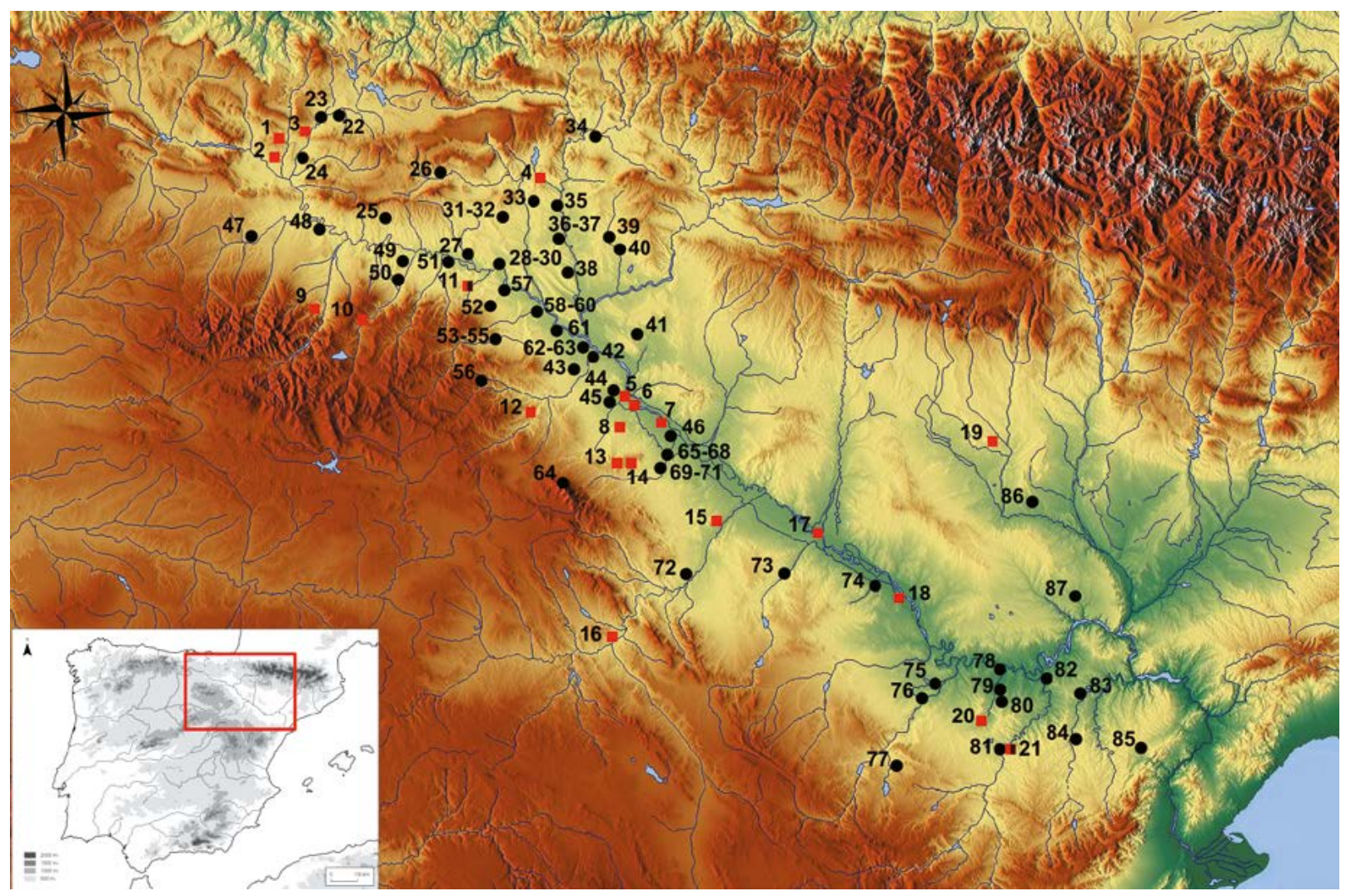

Fig. 1. Representación de yacimientos con cerámica excisa en el valle medio del Ebro. Con símbolo cuadrado, yacimientos de Cogotas I. Álava: 1. Solacueva de Lacozmonte (Jokano); 2. La Paul (Arbigano); 3. La Teja (Villodas). Navarra: 4. Dolmen de Charracadía (Cirauqui); 5. Marijuan VI (Tudela); 6. Monte Aguilar (Bardenas Reales); 7. El Bocal (Fontellas); 8. Cabezo de La Mesa (Ablitas). La Rioja: 9. Majada Londeras (Tobía); 10. Cueva de San Bartolomé (Nestares); 11. Partelapeña (El Redal); 12. Cueva de los Lagos (Aguilar del Río Alhama). Aragón: 13. Majaladares (Borja); 14. Moncín (Borja); 15. Peña Amarilla (Urrea de Jalón); 16. Castillo de los Almantes (Calatayud); 17. Mina Real (Zaragoza); 18. Tozal del Burgo (Pina de Ebro); 19. Torrollón (Usón); 20. Cabezo Sellado y 21. Cabezo del Cuervo (Alcañiz). Con símbolo circular, yacimientos de Campos de Urnas: Álava: 22. Castillo de Henayo (Alegría); 23. Kutzumendi (Vitoria); 24. San Formerio (Pangua); 25. Cueva de los Husos I (Elvillar). Navarra: 26. Santa Coloma (Mendaza); 27. El Rincón (Mendavia); 28. El Castillar/El Viso (Lodosa), 29. El Encinillo y 30. El Mochón (Lodosa); 31. San Miguel (Barbarín); 32. Arrosia (Arróniz); 33. Turturmendía (Oteiza); 34. Pamplona; 35. El Castillo (Larraga); 36. El Alto Hundido y 37. Panadiago (Miranda de Arga); 38. La Atalaya (Falces); 39. Falconera (Olite); 40. El Cerco (Beire); 41. Cabezo de la Modorra I (Bardenas Reales); 42. El Castillo (Castejón); 43. Peña del Saco (Fitero); 44. Santa Bárbara y 45. Castillo de Mirapeix (Tudela); 46. Alto de la Cruz (Cortes). La Rioja: 47. Libia (Herramélluri); 48. San Pelayo (Gimileo); 49. La Coronilla (Lardero); 50. Santa Ana (Entrena); 51. El Sequero (Arrúbal); 52. Camino del Monte- sobre La Tejera- (Tudellila); 53. San Pedro Mártir, 54. Raposeras y 55. S. Fruchos (Arnedo); 56. Muro de Aguas pueblo; 57. Las Caracolas (Pradejón); 58. Torre de Campobajo, 59. La Marcú I y 60. Cabezo de Sorbán (Calahorra); 61. Cabezo la Torre (Aldeanueva de Ebro); 62. Eras de San Martín y 63. Araciel (Alfaro). Aragón: 64. Faldas del Moncayo; 65. El Convento (Mallén); 66. Burrén y Burrena, 67. La Cruz (Fréscano) y 68. El Morredón (Fréscano); 69. Cabecico Aguilera (Agón); 70. Carracierzo (Bisimbre); 71. El Quez (Alberite de San Juan); 72. El Calvario (Calatorao); 73. Lugar Viejo (María de Huerva); 74. Cabezo Morrudo (Fuentes de Ebro); 75. La Pileta (Jatiel); 76. Cabezo de las Mil Rocas (Samper de Calanda); 77. Castelillo (Alloza); 78. Cabezo Torrente (Chiprana); 79. Palermo IV y 80. Záforas (Caspe); 81. Cabezo de Siriguarach (Alcañiz); 82. Cabezo de Monleón (Caspe); 83. Roquizal del Rullo (Fabara); 84. San Cristóbal (Mazaleón); 85. Tossal del Moro (Batea); 86. Las Valletas (Sena); 87. Tozal de Cabezo la Vieja (Candasnos); (en color en la versión electrónica).

El Nivel II, estrato c2 del sondeo de 1979, aportó escasos materiales cerámicos. Son similares a los del nivel anterior, con reiteración de formas y decoraciones. Parece corresponder a una remodelación de una vivienda de la fase III. Una escápula de vacuno (Beta 325722) ha proporcionado una fecha de 2580 $\pm 30 \mathrm{BP}$.
El Nivel I, estrato c4 de 1979, coincide con una agrupación irregular de cantos con cierta alineación que pudiera corresponder a un muro de tendencia circular, junto a restos de cenizas de un posible hogar. La datación absoluta (Beta-325720) sitúa el estrato en $2960 \pm 30$ BP, y coincide con los momentos finales del Bronce Tardío. La fecha es comparable con las de 
la cueva de San Bartolomé en Nestares. El nivel I de entrada a la cavidad fue datado en $2950 \pm 40$ BP y $2970 \pm 25$ BP, y los enterramientos del interior en 2970 \pm 50 BP (Rodanés 1995: 45). Ya al interpretar el contexto destacamos la posibilidad de que se pudiera relacionar con el nivel inferior de la estratigrafía de Partelapeña (Rodanés 1995: 73).

\subsubsection{El Sequero (Arrúbal, La Rioja)}

El paraje se ubica en el polígono industrial de El Sequero en Arrúbal enclavado en la ribera del Ebro. En febrero de 2003 aparecieron los primeros indicios de un yacimiento en la construcción de una central térmica de ciclo combinado. La intervención de urgencia llevada a cabo por L. Gil Zubillaga sacó a la luz dos estructuras, excavadas en su totalidad, estudiadas y publicadas recientemente (Rodanés et al. 2016).

En la memoria, con distintos argumentos, se analizan diferentes hipótesis, se explica la evolución deposicional y postdeposicional de los niveles y se justifica la interpretación de los hallazgos como fondos de cabaña o en su caso restos de viviendas semisubterráneas (pithouses o dwelling-pits). Ambas estructuras necesariamente estuvieron interrelacionadas. Es posible que la $\mathrm{n}^{\circ} 2$ no se ocupara o fuese abandonada en beneficio de la primera, convirtiéndose en una fosa secundaria utilizada en momentos puntuales como basurero. El conjunto de restos respondería a una residencia secundaria de carácter familiar, satélite o dependiente de un poblado principal de mayores dimensiones. Sería la plasmación de la vertebración del territorio derivada de la colonización y explotación intensiva de los terrenos llanos y aluviales del valle del Ebro (Rodanés et al. 2016: 105-106).

La ocupación según las dataciones de C14 se extiende a lo largo del siglo IX cal AC. El material más significativo y casi exclusivo es la cerámica, mayoritariamente procedente de la estructura 1. En ella se inventariaron 1061 fragmentos cerámicos, reconstruyéndose un mínimo de 96 vasos, 34 de ellos con su perfil completo, con una alta proporción de formas de mesa y almacenaje. Destacan algunos recipientes por su decoración a base de incisiones, excisiones, elementos plásticos e impresiones. Las decoraciones excisas son especialmente significativas para el tema de este trabajo, siendo los motivos más repetidos zigzag en altorrelieve y ajedrezado, y minoritariamente rombos en altorrelieve y rectángulos excisos. El espacio decorado con excisión está siempre delimitado por motivos incisos. Esta combinación de excisión, incisión e impresión aparece indistintamente en vasos de pequeño y gran tamaño, siempre en recipientes con pastas depuradas y acabados bruñidos (Fig. 2).
De los siete vasos decorados con excisión seis corresponden a la estructura 1. Los perfiles habituales son bitroncocónicos, de carena media-alta y cuello exvasado. Los encontramos en el valle medio del Ebro coincidiendo con la Fase I del Cabezo de la Cruz (La Muela), en este caso sin decoración excisa, bien datados entre finales del siglo X e inicios del IX cal AC y la segunda mitad del IX cal AC (Picazo y Rodanés 2009: 247). Se corresponden con la forma 4 de la clasificación de Álvarez y Pérez Arrondo (1987: 105, Fig. 44). También se identifican platos o cuencos con decoración en el interior $\mathrm{y}$, en menor proporción, vasos de almacenaje, coincidiendo con los tipos 1 y 2, forma 4 y 5 de dicha clasificación (Álvarez y Pérez Arrondo 1987: 105).

El yacimiento más significativo por cercanía, relevancia, documentación y afinidades formales es Partelapeña. En el ya comentado nivel III, los motivos ornamentales más complejos corresponden a excisión e impresión y se caracterizan por su configuración geométrica: triángulos, zig-zag, cuadrángulos, rombos, figuras romboidales y franjas paralelas. En él están presentes todos los motivos detectados en El Sequero y predominan los tipos asociados a Campos de Urnas que conviven con las típicas decoraciones acanaladas. Encontramos materiales cerámicos comparables en poblados riojanos como Cerro de Santa Ana (Entrena), Cabezo de la Torre (Aldeanueva de Ebro), Las Caracolas (Pradejón), Sorbán (Calahorra), Raposal y San Miguel (Arnedo) y Eras de San Martín (Alfaro). Todos ocupan las fértiles tierras aluviales junto a los cauces de los ríos afluentes del Ebro por su margen derecha (Rodanés et al. 2016: 73).

\subsubsection{El Morredón (Fréscano, Zaragoza)}

Este poblado ubicado en las proximidades del río Huecha, tras ser descubierto en los años 1970, fue objeto de distintas intervenciones cuyos materiales han dado lugar a varias noticias y publicaciones (Royo 2005).

Entre 2002 y 2004 se desarrollaron tres extensas campañas de excavación dirigidas por J. Navarro que permanecían inéditas y están siendo actualmente objeto de estudio como parte de la tesis doctoral de uno de los firmantes (PA-C). Las actuaciones se centraron en una serie de estructuras en la parte sudoeste del cerro y en un área amesetada en la zona noreste, que corroboraron la existencia de un poblado aterrazado con ocupación desde el Bronce Tardío hasta la Primera Edad del Hierro.

La fase III de poblado, de la Primera Edad Hierro, se documenta en las dos áreas intervenidas. En la parte superior se conservan diferentes remodelaciones del

Trab. Prehist., 76, N. ${ }^{\circ}$ 1, enero-junio 2019, pp. 84-101, ISSN: 0082-5638

https://doi.org/10.3989/tp.2019.12227 

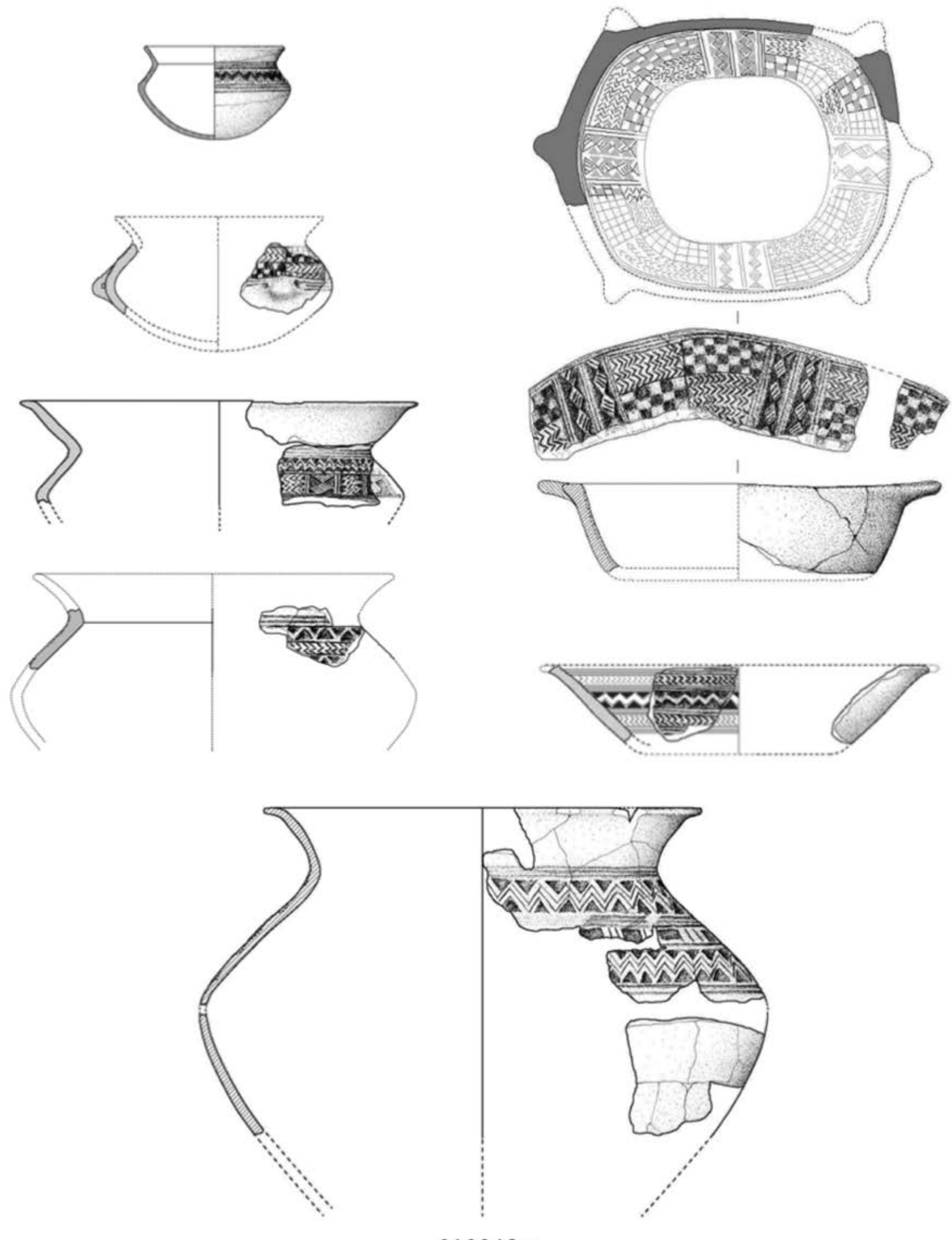

Fig. 2. Formas y motivos excisos de El Sequero (Arrúbal, La Rioja). Dibujos realizados por M. ${ }^{a}$ Cruz Sopena Vicién.

Trab. Prehist., 76, N. ${ }^{\circ}$ 1, enero-junio 2019, pp. 84-101, ISSN: 0082-5638 https://doi.org/10.3989/tp.2019.12227 
pavimento y los cimientos de varios muros, estructuras de combustión y agujeros de postes. El arrasamiento ha destruido los niveles de ocupación y la mayor parte de las estructuras, siendo difícil la definición de espacios. En la ladera sudoeste se suceden estructuras de planta rectangular, en algunos casos excavadas en la roca natural del cerro, con zócalos de piedra y levantamientos de manteados de barro que, a pesar de su pobreza estructural (ausencia de hogares, bancos corridos o muros divisorios), podemos interpretar como espacios domésticos. Se ha datado un fragmento de carbón procedente del nivel de derrumbe: $2484 \pm 22$ BP (D-AMS 021824). Los materiales cerámicos son similares al repertorio característico del período en el valle medio del Ebro, con perfiles de cuello cilíndrico y cuerpo globular y platos troncocónicos, mayoritariamente sin decoración (Aranda-Contamina et al. 2016).

El Bronce Final, la fase II del poblado, se identifica solamente en la zona noreste del cabezo. La fuerte erosión y el aterrazamiento de los niveles posteriores han provocado una escasa potencia estratigráfica y una cierta pobreza estructural. Se conservan niveles de relleno y regularización y un pavimento extendido por gran parte de la cuadrícula con escasas estructuras asociadas. La horquilla de dataciones se sitúa entre $2826 \pm 37$ BP (D-AMS 021820) y del pavimento inmediatamente superior, $2799 \pm 33$ BP (D-AMS 021822). Los materiales son mayoritariamente cerámicos: perfiles bitroncocónicos con carena y cuello exvasado con ocasionales decoraciones incisas, excisas y de boquique. Tipologías similares definen el PIII del Alto de la Cruz de Cortes (Maluquer et al. 1990: 5762). Entre decoraciones excisas, el motivo predominante es el de triángulos excisos, y en menor medida, zigzag en altorrelieve, rombos y rectángulos excisos. Estos aparecen siempre combinados con motivos incisos que delimitan los espacios decorados y los triángulos en altorrelieve, generalmente líneas oblicuas. Minoritariamente la excisión se combina con boquique e impresión. Se dispone en vasos de pequeño tamaño, generalmente con acabados pulidos, forma bitroncocónica con carena en posición media, con la excepción de un fragmento de cuerpo globular y cuello cilíndrico con motivos de rombos excisos localizado en superficie (Fig. 3).

Por último, el nivel del Bronce Tardío, fase I, se ha identificado en una unidad estratigráfica de relleno y nivelación del pavimento del Bronce Final, con una fecha de $2946 \pm 29$ BP (D-AMS 021821). El material cerámico es escaso, poco cohesionado y muy fragmentado. Corresponde a vasos de almacenaje (gruesas paredes con cordones digitados) y de mesa, con perfiles carenados, acabados pulidos y alisados, cuellos rectos y exvasados. En principio, en espera de futuras actuaciones, detectamos una primera ocupación como sucede en el Alto de la Cruz (García López 1994) o la anteriormente citada del nivel inferior de Partelapeña.

\subsection{Una lectura a partir de las fechas C14: aplicación de estadística bayesiana}

Expuesta a grandes rasgos la problemática de la cerámica con decoración excisa en el valle del Ebro, incidiremos en los aspectos cronológicos a partir de la presentación de las nuevas dataciones, mediante estadística bayesiana. Utilizamos los yacimientos con niveles o materiales de Cogotas I del Bronce Tardío (Tab. 1) y los contextos arqueológicos con elementos formales de Campos de Urnas durante el Bronce Final (Tab. 2). Contamos con 9 dataciones para el primero y 15 para el segundo, en su mayoría inéditas o recientemente publicadas. Este desequilibrio numérico entre ambas fases tiene también su reflejo en una desigual distribución espacial (Fig. 1) y, más todavía, en el recuento de hallazgos, donde la representación de Cogotas I se reduce a 21 yacimientos frente a 66 correspondientes al Bronce Final-Campos de Urnas. Las asociadas a Cogotas se localizan casi exclusivamente en la zona del Alto Ebro. Las únicas dataciones de la zona oriental del valle proceden del Cabezo del Cuervo (Alcañiz, Teruel) y, siguiendo a Abarquero (2005: 143, pie de página), han sido descartadas. Las correspondientes al Bronce Final, sin embargo, se reparten por todo el valle medio con dos claros focos: el Bajo Aragón y el valle del Huecha.

Los fundamentos teóricos de la estadística bayesiana, sus posibilidades y limitaciones en su aplicación a la Arqueología han generado una cuantiosa bibliografía (Bronk Ramsey 1995, 2009; Bayliss et al. 2007; Bayliss 2015; Buck y Meson 2015; Hamilton y Kruss 2017). Creemos, aún así, que su aplicación puede completar, incluso matizar, la mera exposición de fechas calibradas y contribuir a un mejor conocimiento de la dinámica temporal.

La modelización se ha realizado mediante el software OxCal v. 4.3 (Bronk Ramsey 2009), agrupando las dataciones en dos fases según el grupo cultural. Se ha recurrido a un modelo trapezoidal de fases contiguas, ya que consideramos el empleo de la técnica de decoración excisa fruto de un continuum, a pesar del más que probable origen y desarrollo independiente de las dos realidades sociales y culturales. Por otra parte, el modelo trapezoidal, recientemente incorporado al software OxCal, frente al uniforme aplicado por defecto (Bronk Ramsey y Lee 2013), permite un inicio, un final y una transición igualmente gradual entre fases, aplicándose, por tanto, a fenómenos en los que no puede asumirse un evento inicial 

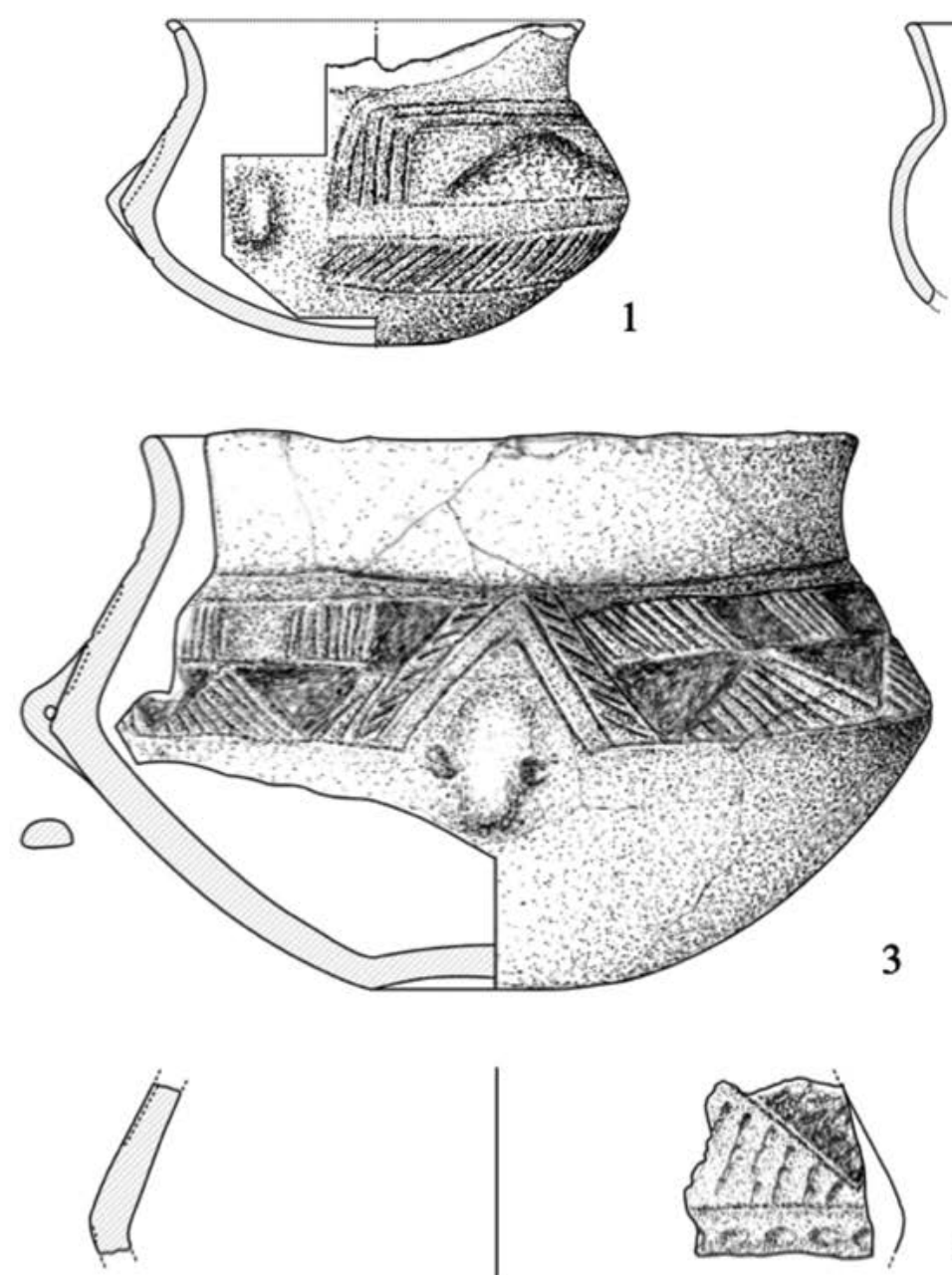

1

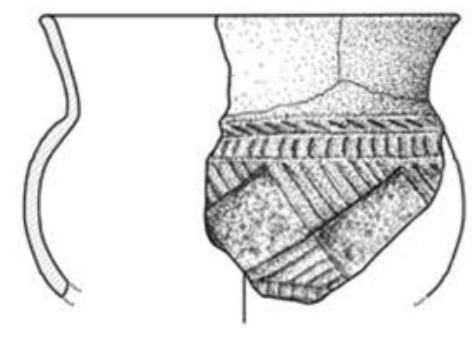

2

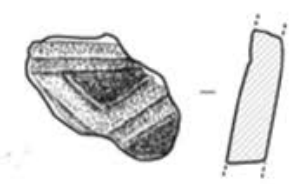

5
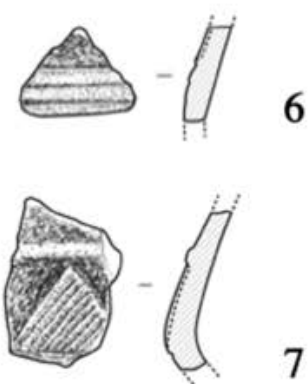

7

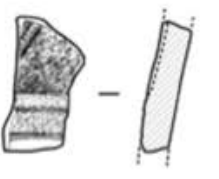

8

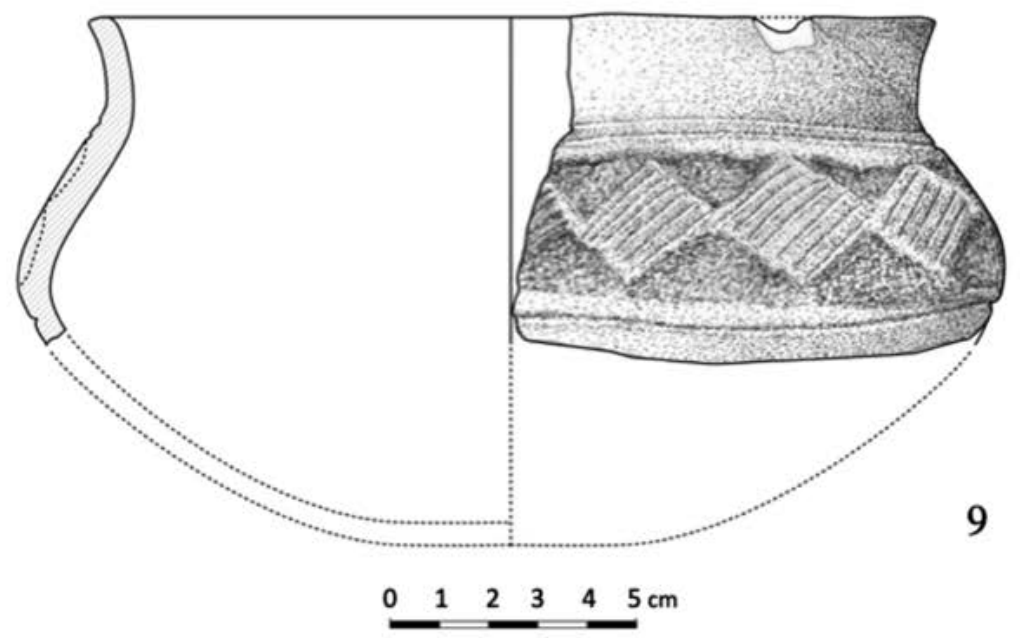

Fig. 3. Formas y motivos excisos de dos yacimientos del valle del Huecha (Aragón): 1-8. El Morredón; 9. Burrén y Burrena. Dibujos realizados por M. ${ }^{\text {a }}$ Cruz Sopena Vicién. 
y final rotundo y seguro (Karlsberg 2006; Lee y Bronk Ramsey 2012).

Conscientes de la problemática en torno a la utilización de fechas radiocarbónicas procedentes de excavaciones antiguas, cuyo contexto no es bien conocido y puede haber contaminaciones (Bayliss 2015: 683-690; Pettitt y Zilhao 2015), se ha prescindido de algunas de ellas tras someterlas a la necesaria valoración crítica, tanto por no proceder de contextos seguros, como por dudar de su fiabilidad o haber sido identificadas como outliers ${ }^{8}$. Las descartadas son tres dataciones de Moncín (Borja, Zaragoza), aunque todo el conjunto debe ser utilizado con precaución al tratarse de un asentamiento carente de estratigrafía vertical que metodológicamente no aportaría datos adicionales a la estadística. No obstante hemos decidido mantener las más fiables. Ha sido excluida la muestra con sigla BM-2607 por la discrepancia señalada por los propios investigadores con la datación BM-2606, procedente del mismo nivel IIA pero de un contexto más fiable (Harrison et al. 1994: 159). Las muestras BM-1926R y BM-2193R han sido descartadas por su escasa fiabilidad al ser resultado de la recalibración de las fechas originales afectadas por un error sistemático del Radiocarbon Laboratory del Museo Británico de Londres (Moreno y Harrison 1990: 14 y 15). Las series más completas y fiables son las que ahora damos a conocer, en especial las de El Morredón, Partelapeña y El Sequero.

Como resultado de la aplicación del modelo propuesto, hemos definido los momentos de inicio y final de la decoración excisa en el valle del Ebro, así como el intervalo de transición entre los dos grupos culturales en los que aparece. El índice de correlación general del modelo es consistente $\left(\mathrm{A}_{\text {overall }}\right.$ 106.5). Los resultados obtenidos se encuentran en distribuciones de probabilidad del 68,2 \% y 95,4 \% (Fig. 4).

El inicio de la cerámica excisa, Cogotas I, en la zona estudiada se situaría entre 1397-1139 cal AC (95\% de probabilidad), probablemente entre 13071187 cal AC (68 \%). El momento de transición entre la fase anterior y Campos de Urnas se produciría entre $1176-981$ cal AC (95\%) y entre 1140-1043 cal AC $(68 \%)$, mientras el final quedaría enmarcado entre el $826-632$ cal AC (95\%) y entre $785-718$ cal AC (68 \%) (Fig. 5).

La datación más antigua de un contexto de Cogotas I con cerámica excisa se localiza en Moncín, entre 1350 y 1115 cal AC (95\%) y 1273 y 1129 cal AC (68\%), seguido de las de dos yacimientos riojanos: la

\footnotetext{
${ }^{8}$ Se definen así las dataciones radiocarbónicas con un índice de correlación (agreement index) significativamente menor del $60 \%$, indicativo de su falta de consistencia dentro del modelo (Bronk Ramsey 2009: 356-357).
}

\begin{tabular}{|c|c|c|c|c|c|c|c|c|c|}
\hline 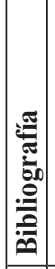 & 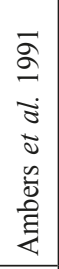 & 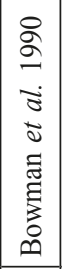 & 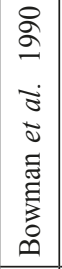 & 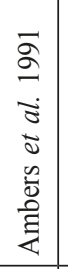 & 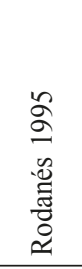 & 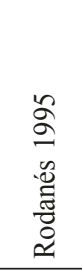 & 莺 & 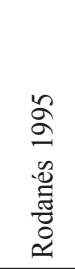 & 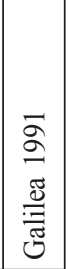 \\
\hline | & 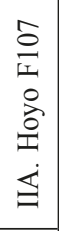 & $\begin{array}{l}\dot{m} \\
\vec{d} \\
\stackrel{\vec{z}}{z} \\
\dot{=}\end{array}$ & 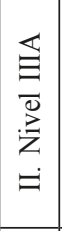 & 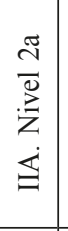 & 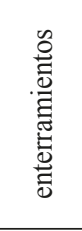 & 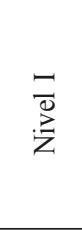 & 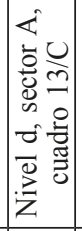 & $\frac{\vec{D}}{\vec{z}}$ & \\
\hline 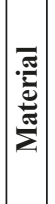 & 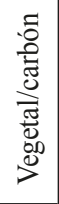 & 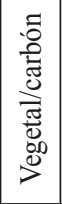 & 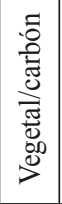 & 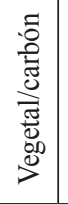 & 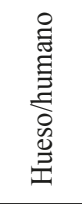 & 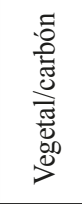 & 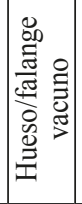 & 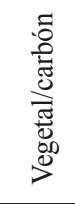 & 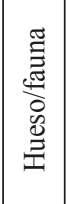 \\
\hline 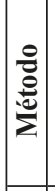 & 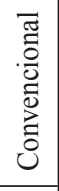 & 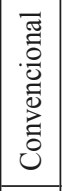 & 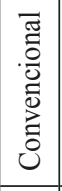 & 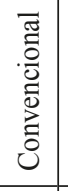 & 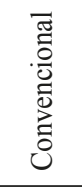 & 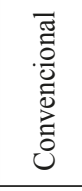 & $\sum_{i}^{\infty}$ & $\begin{array}{l}\bar{\Xi} \\
\overline{0} \\
\overline{0} \\
\overline{0} \\
\overrightarrow{0} \\
0\end{array}$ & \\
\hline $\begin{array}{l}0 \\
2 \\
2\end{array}$ & 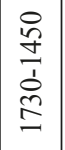 & $\begin{array}{l}\stackrel{8}{\circ} \\
\stackrel{1}{1} \\
\stackrel{0}{0} \\
\infty\end{array}$ & $\begin{array}{l}\stackrel{0}{0} \\
\frac{1}{1} \\
\frac{1}{6} \\
-\end{array}$ & 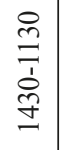 & 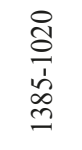 & 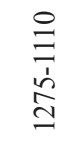 & 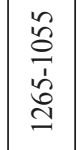 & 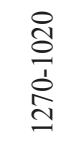 & 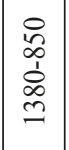 \\
\hline $\begin{array}{l}0 \\
0 \\
\infty \\
0\end{array} \mid$ & 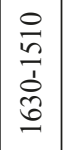 & 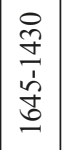 & 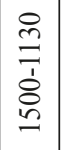 & 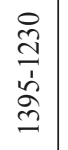 & 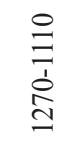 & 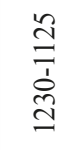 & 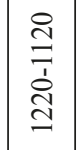 & 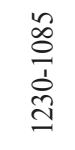 & $\begin{array}{l}\stackrel{n}{a} \\
\hat{a} \\
\stackrel{a}{a} \\
=\end{array}$ \\
\hline 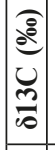 & ' & ' & ' & ' & ' & ' & 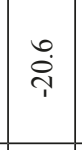 & ' & \\
\hline$\left|\begin{array}{l}\vec{\alpha} \\
\vec{v} \\
\bar{v}\end{array}\right|$ & $\begin{array}{l}0 \\
n \\
+1 \\
8 \\
8 \\
m \\
m\end{array}$ & $\begin{array}{l}8 \\
0 \\
+1 \\
8 \\
i \\
m\end{array}$ & $\begin{array}{l}\text { I } \\
+ \\
+1 \\
\stackrel{0}{0} \\
0 \\
m\end{array}$ & $\begin{array}{l}0 \\
i n \\
+1 \\
0 \\
o \\
0 \\
n\end{array}$ & $\begin{array}{l}8 \\
n \\
+1 \\
尺 \\
\stackrel{0}{0}\end{array}$ & 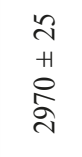 & $\begin{array}{l}\text { D } \\
+ \\
\dot{0} \\
\stackrel{0}{0}\end{array}$ & $\begin{array}{l}\stackrel{+}{ } \\
+ \\
\stackrel{0}{2} \\
\stackrel{2}{i}\end{array}$ & $\begin{array}{l}n \\
\infty \\
+1 \\
8 \\
\grave{2}\end{array}$ \\
\hline 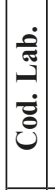 & 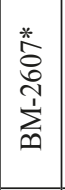 & 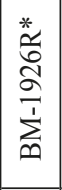 & 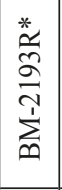 & $\begin{array}{l}\stackrel{0}{8} \\
0 \\
\sum_{\infty}^{1}\end{array}$ & $\frac{n}{\frac{n}{6}}$ & 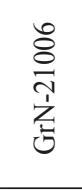 & 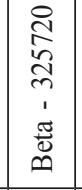 & 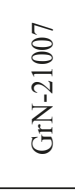 & 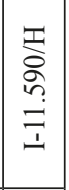 \\
\hline 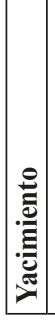 & 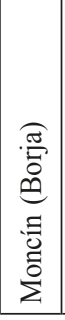 & 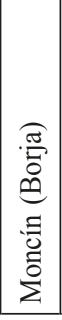 & 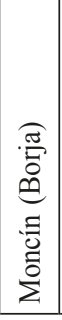 & 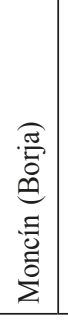 & 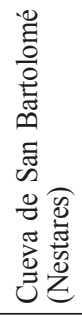 & 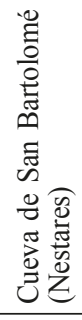 & 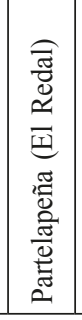 & 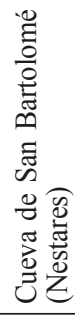 & 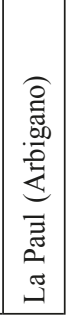 \\
\hline
\end{tabular}

Trab. Prehist., 76, N. ${ }^{\text {o }}$ 1, enero-junio 2019, pp. 84-101, ISSN: 0082-5638

https://doi.org/10.3989/tp.2019.12227 


\begin{tabular}{|c|c|c|c|c|c|c|c|c|c|c|c|c|c|}
\hline 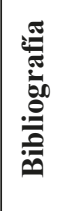 & 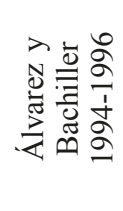 & 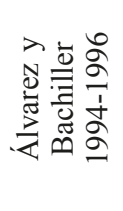 & 䔅 & 异 & 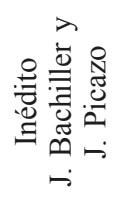 & 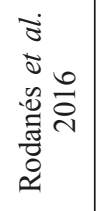 & 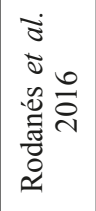 & 韋 & 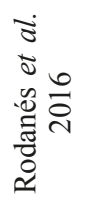 & 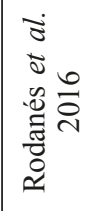 & 韋 & 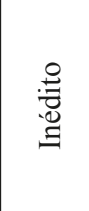 & 总 \\
\hline ن⿺辶大 & 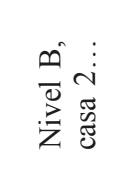 & 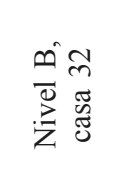 & 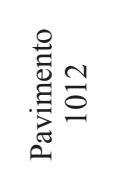 & 苞 & 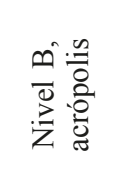 & 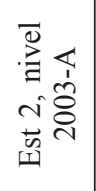 & 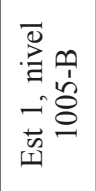 & 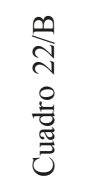 & 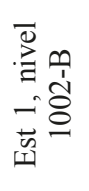 & 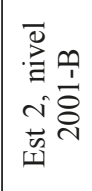 & 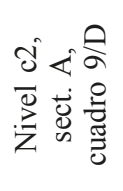 & 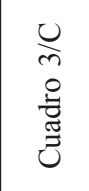 & 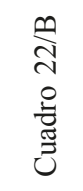 \\
\hline 离 & ' & ' & 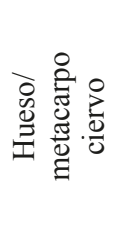 & 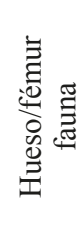 & 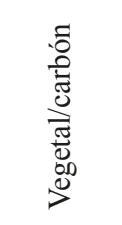 & 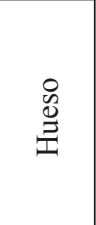 & 号 & 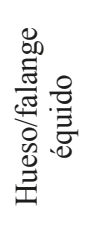 & 品 & 邑 & 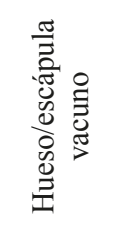 & 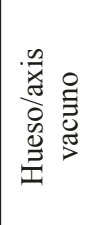 & 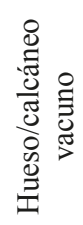 \\
\hline : & ' & ' & $\sum_{k}^{\infty}$ & $\sum_{4}^{\infty}$ & 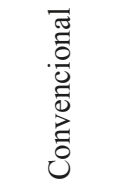 & $\sum_{<}^{\infty}$ & $\sum_{<}^{\infty}$ & $\sum_{4}^{\infty}$ & $\sum_{4}^{\infty}$ & $\sum_{<}^{\infty}$ & $\sum_{<}^{\infty}$ & $\sum_{<}^{\infty}$ & $\sum_{<}^{\infty}$ \\
\hline$\frac{0}{2}$ & 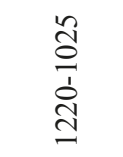 & $\begin{array}{l}\text { \& } \\
\text { à } \\
\stackrel{\Xi}{=}\end{array}$ & \begin{tabular}{l}
8 \\
\multirow{1}{1}{} \\
$\vdots$ \\
$=$
\end{tabular} & \begin{tabular}{l} 
in \\
$\infty$ \\
1 \\
1 \\
\multirow{2}{0}{} \\
0
\end{tabular} & 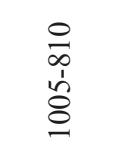 & 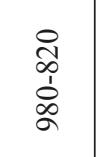 & 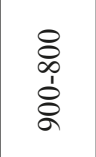 & 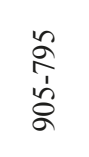 & 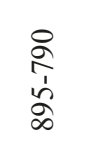 & $\begin{array}{l}\stackrel{2}{人} \\
\grave{1} \\
\grave{\infty}\end{array}$ & $\begin{array}{l}n \\
\infty \\
n \\
n \\
\infty\end{array}$ & $\begin{array}{l}n \\
\hat{n} \\
0 \\
\infty \\
\infty\end{array}$ & 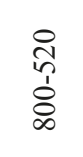 \\
\hline $\begin{array}{l}\stackrel{\theta}{0} \\
\infty\end{array}$ & 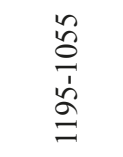 & $\begin{array}{l}8 \\
8 \\
1 \\
\vdots \\
=\end{array}$ & $\begin{array}{l}\text { ลे } \\
\text { ஸे } \\
\text { லे }\end{array}$ & $\begin{array}{l}0 \\
\text { aे } \\
\delta \\
8 \\
0\end{array}$ & 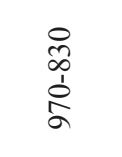 & 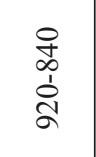 & $\begin{array}{l}n \\
2 \\
\infty \\
1 \\
\alpha \\
\infty\end{array}$ & $\begin{array}{l}2 \\
2 \\
\\
\infty\end{array}$ & 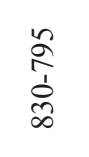 & 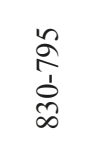 & $\begin{array}{l}\stackrel{R}{\hat{i}} \\
\hat{1} \\
\stackrel{\infty}{\infty}\end{array}$ & $\begin{array}{l}\hat{2} \\
\hat{1} \\
\hat{2}\end{array}$ & $\begin{array}{l}n \\
\hat{n} \\
\vdots \\
2 \\
2\end{array}$ \\
\hline$\underbrace{\grave{0}}_{\frac{e}{\infty}}$ & ' & ' & ' & ' & 1 & $\frac{m}{7}$ & $\frac{\partial}{\frac{9}{1}}$ & $\underset{\vec{\top}}{\exists}$ & $\frac{n}{1}$ & $\underset{\text { Tे }}{\stackrel{0}{i}}$ & $\overrightarrow{\vec{\lambda}}$ & 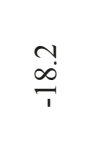 & $\stackrel{\infty}{\stackrel{\infty}{\rightarrow}}$ \\
\hline $\begin{array}{l}\overrightarrow{\hat{\theta}} \\
\vec{\Xi}\end{array}$ & $\begin{array}{l}0 \\
\text { H } \\
0 \\
\infty \\
\text { ते }\end{array}$ & $\begin{array}{l}2 \\
i \\
+1 \\
尺 \\
\infty \\
\text { N }\end{array}$ & $\begin{array}{l}\text { n } \\
+1 \\
\text { D } \\
\infty \\
\text { N }\end{array}$ & $\begin{array}{l}m \\
\text { H } \\
\stackrel{2}{\hat{~}}\end{array}$ & $\begin{array}{l}0 \\
i \\
+1 \\
o \\
\stackrel{n}{N}\end{array}$ & $\begin{array}{l}0 \\
i \\
+1 \\
o \\
\stackrel{n}{N} \\
\end{array}$ & $\begin{array}{l}0 \\
\text { H } \\
+1 \\
\text { Q } \\
\text { iे }\end{array}$ & $\begin{array}{l}\text { \& } \\
+1 \\
0 \\
\stackrel{2}{0}\end{array}$ & 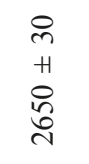 & 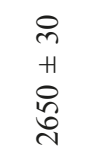 & $\begin{array}{l}0 \\
\text { r } \\
+1 \\
0 \\
\infty \\
\end{array}$ & $\begin{array}{l}8 \\
\text { r } \\
+1 \\
8 \\
i n \\
i n\end{array}$ & $\begin{array}{l}\text { } \\
H \\
\text { त } \\
\text { ปे }\end{array}$ \\
\hline 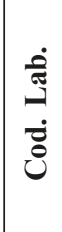 & 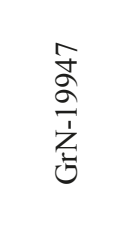 & $\frac{\stackrel{2}{2}}{\frac{1}{2}}$ & 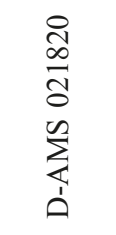 & 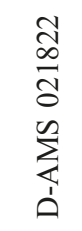 & 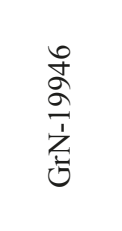 & 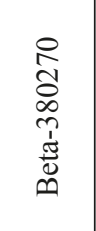 & 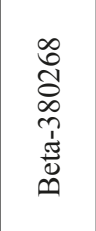 & 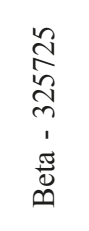 & $\begin{array}{l}\hat{D} \\
\widetilde{D} \\
\infty \\
\tilde{n} \\
\tilde{\tilde{c}} \\
0 \\
0\end{array}$ & 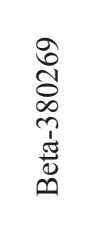 & $\begin{array}{l}\text { ते } \\
\text { ñ } \\
m \\
1 \\
\vdots \\
0 \\
\infty\end{array}$ & 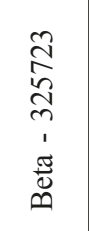 & $\begin{array}{l}\underset{N}{N} \\
\text { N } \\
\infty \\
1 \\
\vdots \\
\infty \\
\infty\end{array}$ \\
\hline 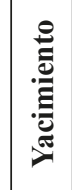 & 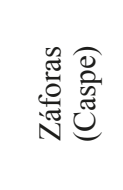 & 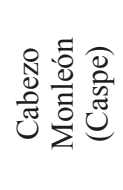 & 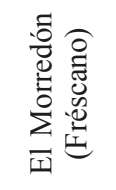 & 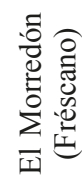 & 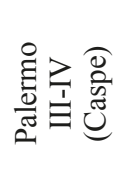 & 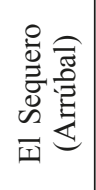 & 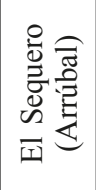 & 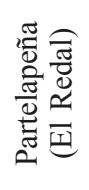 & 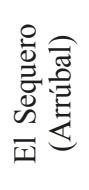 & 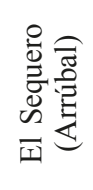 & 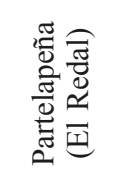 & 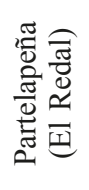 & 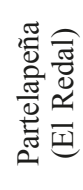 \\
\hline
\end{tabular}


cueva de San Bartolomé y el nivel I de Partelapeña. La más reciente pertenece al Hoyo La Paul (Álava), entre 1279 y 1021 cal AC (95\%) y 1216 y 1101 $(68 \%)$.

Las dataciones más antiguas de contextos con cerámica excisa del Bronce Final pertenecen a los yacimientos bajoaragoneses de Záforas y el Cabezo de Monleón. Ligeramente más recientes son las de El Morredón, la estructura 2 de El Sequero, ya en La Rioja, y la de Palermo III-IV (Caspe). Las dataciones del estilo Redal se concentran entre la más antigua de El Sequero (estructura 2), entre 976 y 822 cal AC $(95 \%)$ y 916 y $844 \mathrm{cal} \mathrm{AC} \mathrm{(68 \% ),} \mathrm{y} \mathrm{la} \mathrm{más} \mathrm{reciente}$ de Partelapeña (cuadro 22/B), entre 805 y 666 cal AC $(95 \%)$ y 793 y $754 \mathrm{cal} \mathrm{AC} \mathrm{(68 \% ).} \mathrm{Este} \mathrm{grupo} \mathrm{reúne}$ las fechas más recientes, lo que puede deberse a la presencia ligeramente más tardía de elementos formales de Campos de Urnas en el alto valle del Ebro, por lo que la adaptación de la excisión a las nuevas formas también lo sería. Hoy por hoy, los resultados muestran mayor antigüedad en los yacimientos del Bajo Aragón y del valle del Huecha que en las tierras riojanas. Esto se podría interpretar como la adaptación de la técnica de decoración excisa a las nuevas formas de Campos de Urnas que aparecen más tardíamente en el occidente del valle. Así se explicaría la anterioridad de la alfarería excisa aragonesa, frente al estilo Redal-Sequero cuyas dataciones difieren más de un siglo. No obstante, debemos ser prudentes y tomar esos datos con cautela ya que las fechas bajoaragonesas son escasas, frente a las series proporcionadas por el resto de yacimientos situados aguas arriba, y los contextos arqueológicos no han sido convenientemente publicados y justificados.

Si se aceptaran estos datos cabría sugerir como hipótesis la presencia de Cogotas I en el valle medio del Ebro durante el Bronce Tardío con yacimientos relevantes como Moncín o Majaladares, junto a lugares con escasos, incluso descontextualizados, fragmentos cerámicos. Los mapas de distribución dan una buena idea de la implantación (Fig. 1) explicada por diferentes mecanismos (Abarquero 2012: Figs. 2 a 6). La técnica excisa evidentemente estaría presente de manera habitual en estos contextos y utilizada por las poblaciones que mayoritariamente se diseminan por la margen derecha del Ebro, junto a los valles del Sistema Ibérico. Los escasos ejemplos en la vertiente norte se limitan a yacimientos de Navarra y Álava, o los dos pequeños fragmentos sin estratigrafía de Torrollón II (Huesca) (Rey 1987: 70 y L. 13).

La fase de transición ha quedado igualmente documentada en estratigrafías datadas como las de Partelapeña o El Morredón, incluso en otras no datadas como la de Cueva Lóbrega (Barrios 2004: 120) o Eras de San Martín. Allí se detectó una primera fase asimi- lada a Cogotas I con cerámicas decoradas mediante excisión y boquique, mientras que la superior sería plenamente comparable en materiales al nivel III de Partelapeña (Hernández Vera 1983: 70-71; Álvarez y Pérez Arrondo 1987).

El conocimiento y uso de la técnica alcanza su máximo apogeo durante el Bronce Final. Así la excisión Cogotas I se convierte en un elemento de substrato -nuevas formas, antiguas tradiciones decorativas ${ }^{9}$ - que se incorpora a la vajilla, donde los motivos acanalados son el elemento decorativo principal y hasta entonces ausente. Esto explicaría su presencia en formas de Campos de Urnas, esencialmente bitroncocónicas.

La fase final coincidiría con la Primera Edad del Hierro, bien documentada en recientes estratigrafías con series de dataciones absolutas. Las decoraciones han desaparecido prácticamente e incluso en su totalidad, dando paso a una alfarería lisa con formas específicas como los tipos de cuello cilíndrico y platos troncocónicos bien representados en los poblados superiores del Cabezo de La Cruz de La Muela (Picazo y Rodanés 2009). Observamos este mismo proceso en yacimientos antes comentados: la transición entre la fase II a III de El Morredón, en la III a IV de Partelapeña, incluso entre los niveles inferiores y superiores de Sorbán o P III y P II del Alto de la Cruz de Cortes.

\section{DISCUSIÓN}

En las páginas anteriores hemos tratado de plasmar el estado de la cuestión del origen e implantación de la cerámica con decoración excisa en la península ibérica y de proponer una explicación acorde con los datos que actualmente poseemos en el valle medio del Ebro. Su génesis a escala peninsular presenta todavía muchas sombras. Hoy por hoy, es difícil su explicación $\mathrm{y}$ necesariamente nos hace retomar las discusiones clásicas pero con matices y procesos sustancialmente diferentes. Si pretendemos argumentar su inspiración en ejemplos antes citados y ponemos el acento en el estilo Duffaits con recipientes aparecidos en yacimientos de la Meseta, no deja de ser una vuelta a teorías ya expuestas, excepto en la explicación y el punto de partida del proceso. Deberemos recurrir a otros argumentos ajenos a las clásicas invasiones, oleadas, migraciones o expansiones progresivas que avalarían su presencia, y recurrir a diferentes mecanismos sociales por los que pudieron llegar elementos aislados y configurar relaciones a larga distancia (Delibes et al. 2000:

\footnotetext{
${ }^{9}$ La decoración de boquique, por el contrario, será anecdótica en formas de CC.UU. Señalaremos las piezas del Cabezo de la Torre en Aldeanueva de Ebro o El Morredón en Fréscano.
} 


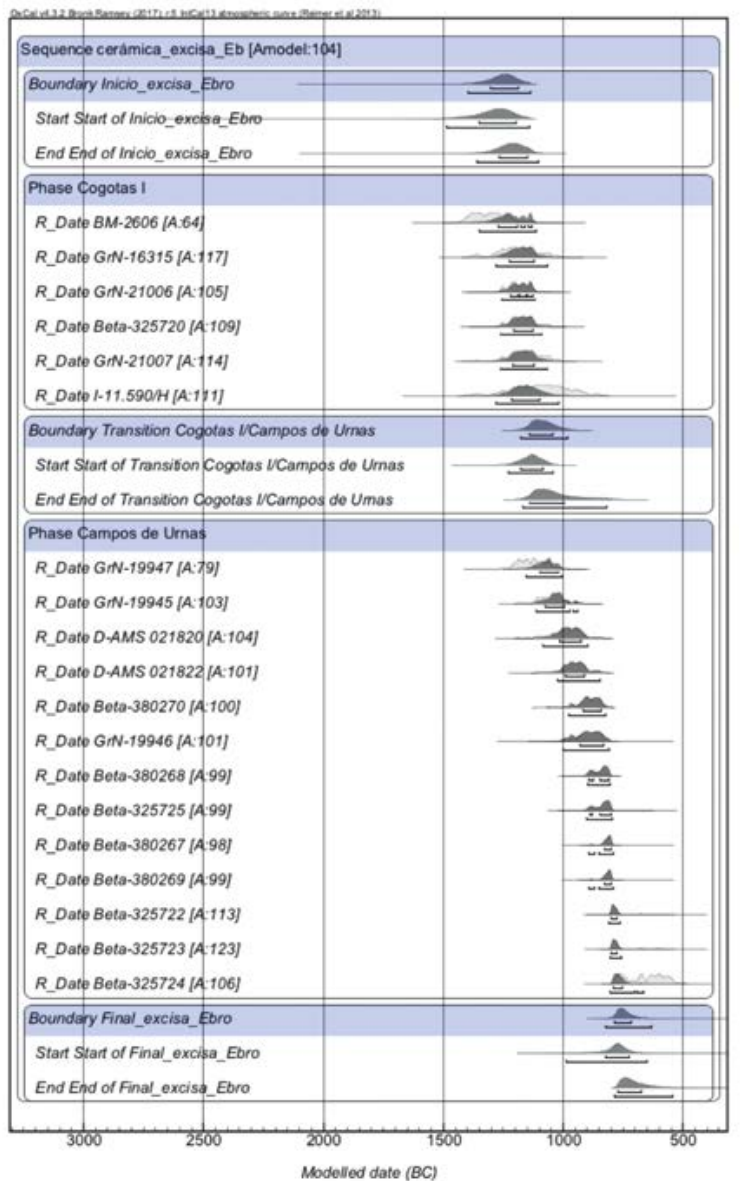

Fig. 4. Modelo contiguo trapezoidal para la cerámica excisa en el valle medio del Ebro $(\mathrm{A}=106.5)$. Realizado en el software OxCal v.4.3 (Bronk Ramsey 2009).

116-123; Blanco 2018: 26). Pero la ausencia casi total de piezas similares en regiones de paso obligado como Aquitania o Pirineos Atlánticos (Roussot-Larroque y Merlet 2012) obligaría a repensar las relaciones entre regiones tan alejadas. Por otra parte, excepto en los casos concretos antes citados, las formas y la sintaxis decorativa no son las mismas. Aun así, no se puede descartar una inspiración o una adaptación de la técnica a las peculiaridades formales y simbólicas de los recipientes meseteños.

Asimismo, tampoco podemos cerrar el debate sobre el origen en las tradiciones de las cerámicas impresas o con incrustaciones tanto para la técnica de boquique como para la posterior excisión. Hay que retrotraerse al Neolítico Antiguo para apreciar los primeros recipientes decorados mediante la técnica de punto y raya, desde ahí a través del complejo campaniforme se imbricarían en Cogotas I (Blanco 2015: 42-44, 2018: 22). No obs-
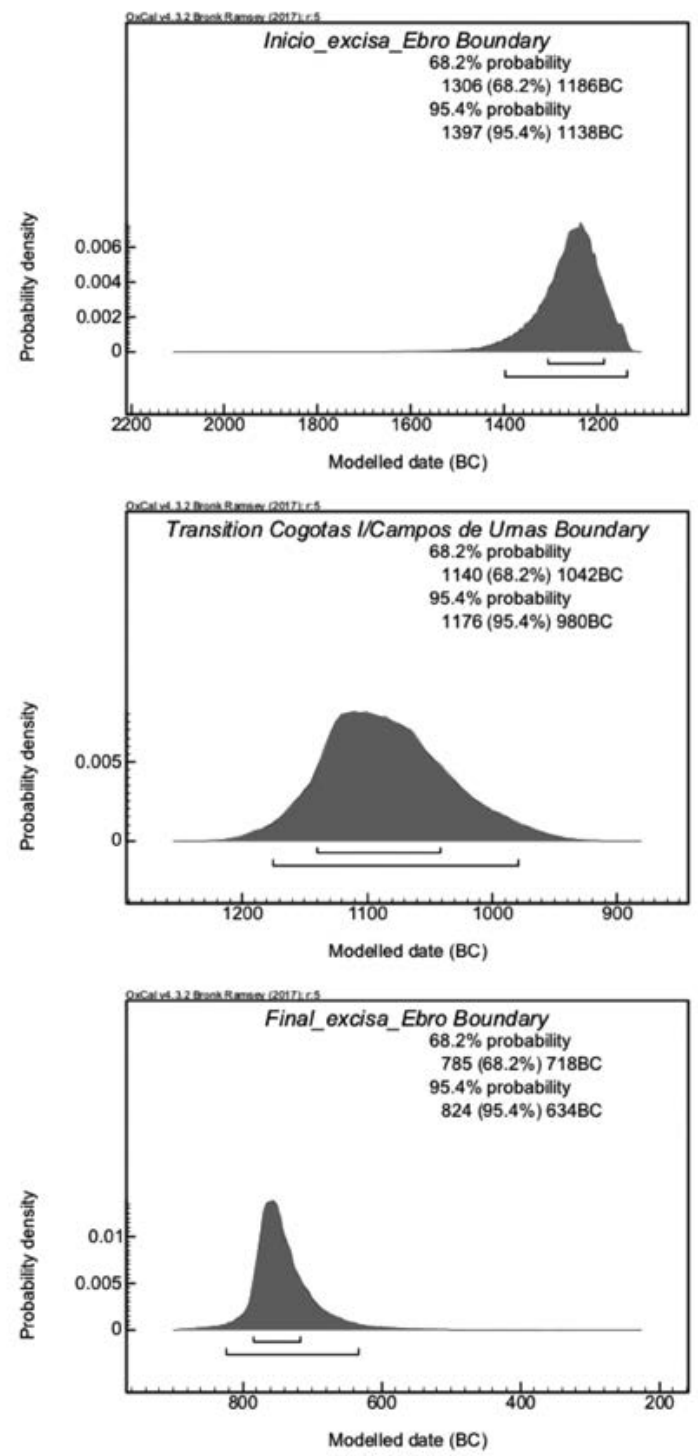

Fig. 5. Distribución de Gauss del momento de inicio, final y transición de la cerámica excisa en el valle medio del Ebro, con la probabilidad del $68 \%$ y $95 \%$ señaladas.

tante, deberemos matizar algunos aspectos. Mayoritariamente se ha hecho alusión a las piezas del interior peninsular, en detrimento de otros territorios como el nordeste. Allí existe esa misma tradición desde el Neolítico (Ramón 2006), continuada durante el Calcolítico y la Edad del Bronce, en unas comarcas donde la presencia campaniforme es muy fuerte y con peculiaridades propias, como el tipo Salomó y su posterior evolución o conversión en Arbolí, bien representado en yacimientos de Cataluña, en especial de Tarragona, y Aragón con secuencias tan importantes como Moncín. Recordemos 
que allí existen vasos con decoración de punto y raya tan antiguos o más que en la zona nuclear de Cogotas (Maya y Petit 1986). No podemos, por tanto, desestimar taxativamente la influencia que su presencia pudo tener en la génesis de las decoraciones del Bronce Tardío, tal como se ha señalado para algunos yacimientos del Bajo Aragón (Álvarez Gracia 1990). Independientemente de estos matices, es evidente que en la Meseta y el valle del Ebro hay periodos "en blanco" en los que la alfarería no recurre a esta técnica, se pierde supuestamente la tradición y el uso, por lo que es difícil explicar su renacimiento. De ahí que hipótesis recientes como la emulación o la copia deliberada de producciones "ancestrales" se pueden tener en cuenta (Blanco 2015: 52, 2018: 27-33), siempre y cuando no se detecten otras posibilidades como los antecedentes señalados entre Parpantique en la cuenca del Duero y los testimonios alfareros de Protocogotas (Rodríguez Marcos 2012: 160).

El problema de la excisión es más complejo. No existe esta modalidad decorativa durante el Neolítico, Calcolítico ni explícitamente en el periodo con campaniforme. Por ello se ha tenido que recurrir desde los primeros trabajos a la denominada pseudoexcisión y a la estética de su composición como antecedente (Almagro Basch 1939), opinión recurrente en ensayos posteriores. Excepto los anteriores paralelos franceses de Duffaits y el singular ejemplo de la Muela del Sabucar en Teruel, curiosamente en un contexto cerámico con decoraciones del grupo Arbolí (Picazo 1993), la excisión en Cogotas, como ya hemos indicado, se incorpora mayoritariamente en momentos plenos y avanzados de su larga trayectoria (Delibes et al. 1990; Rodríguez Marcos 2007: 371, 436-437). Por otra parte, el origen de las pseudoexcisiones de los grupos Salomó y Arbolí plantea grandes incógnitas, ya que precisamente en el noreste donde más influencia y con más intensidad se desarrollaron, en cambio, durante el Bronce Tardío y Final las técnicas de incrustación y la propia excisión tienen menos presencia. La propia excisión falta, p. ej., en Cataluña y el Alto Aragón, donde se desarrollan nuevos y exclusivos tipos de vasos con asas de apéndice de botón y mas tarde los perfiles característicos de Campos de Urnas Antiguos con decoraciones acanaladas.

Tampoco podemos obviar una opción poligenista ya apuntada en las últimas síntesis en Francia (Gómez de Soto 2010, 2013) y enunciado mucho antes por G. Delibes (1978: 241). Tal opción nos llevaría a aceptar un trasfondo cultural común en Europa occidental (Delibes et al. 2000), interconectado por intercambios y relaciones sociales más complejas que las que ahora podemos determinar, trasfondo que a su vez permitiría la eclosión de técnicas o elementos autónomos e independientes, con innegables afinidades. Gómez de
Soto $(2010,2013)$ lo ha propuesto para el centro y suroeste de Francia o las más clásicas desde sus inicios para el grupo de Saint Véredème, que siempre se ha interpretado con una evolución propia a partir de tradiciones del grupo de Ferrières con claras vinculaciones y relaciones apenínicas (Arnal y Riquet 1961).

Para finalizar, una última reflexión. El que unas decoraciones tan características hayan adquirido tal protagonismo debe atribuirse en buena medida a una etapa de las investigaciones excesivamente preocupada por determinar fósiles directores que explicasen las realidades arqueológicas. En la actualidad su presencia o ausencia en el territorio estudiado se contempla dentro de la dinámica de dos periodos trascendentales de la Prehistoria Reciente, el Bronce Tardío y el Bronce Final, con dos grupos culturales de gran personalidad: Cogotas I y Campos de Urnas que durante algunos momentos de su desarrollo confluyeron en este espacio y tiempo concretos. Así, creemos que existen argumentos suficientes para mantener la relación de la alfarería excisa de Cogotas I con la que luego aparece vinculada a Campos de Urnas, en el marco temporal provisionalmente establecido en el apartado anterior. Recordemos que gran parte de este mismo espacio, cercano a la zona nuclear de Cogotas, se ha considerado de contacto y con características muy similares a ella (Abarquero 2012: 67-70). Las mismas hipótesis y reflexiones que intentan explicar su presencia se podrían utilizar para determinar la existencia de estas decoraciones como parte significativa de su bagaje cultural. Desde pequeños movimientos de población, estacionales o no, a otros bien argumentados o criticados como "el espejismo trashumante", "la carreta del mercader", "el ajuar de la novia alfarera", "el reflejo de los otros: emulación de conductas sociales y económicas" o "pequeños presentes" (Abarquero 2012: 93-97). Las nuevas investigaciones permitirán validar o rechazar algunas de estas hipótesis u otras nuevas que se planteen. El debate sigue abierto.

\section{BIBLIOGRAFÍA}

Abarquero, F. J. 2005: Cogotas I. La difusión de un tipo cerámico durante la Edad del Bronce. Arqueología en Castilla y León 4. Junta de Castilla y León. Valladolid.

Abarquero, F. J. 2012: “Cogotas I más allá del territorio nuclear. Viajes, bodas, banquetes y regalos en la Edad del Bronce Peninsular". En J. A. Rodríguez Marcos y J. Fernández Manzano (eds.): Cogotas I. Una cultura de la Edad del Bronce en la Península Ibérica. Homenaje a M. ${ }^{a}$ Dolores Fernández-Posse. Serie Arte y Arqueología 30, Universidad de Valladolid. Valladolid: 59-110.

Almagro Basch, M. 1939: "La cerámica excisa de la I Primera Edad del Hierro en la Península Ibérica”. Ampurias I: 138-158.

Almagro Basch, M. 1952: "La España de las invasiones célticas y el mundo de las colonizaciones". En R. Menéndez Pidal (ed.): Historia de España I, II, Espasa-Calpe. Madrid: 141-240. 
Almagro Gorbea, M. 1977: El Bronce Final y el Periodo Orientalizante en Extremadura. Bibliotheca Praehistorica Hispana XIV, CSIC. Madrid.

Álvarez Clavijo, P. y Pérez Arrondo, C. L. 1987: La cerámica excisa de la Primera Edad del Hierro en el Valle Alto y Medio del Ebro. Col. Historia 8, Instituto de Estudios Riojanos. Logroño.

Álvarez Gracia, A. 1990: El Bronce Final y el Hierro Inicial en la región aragonesa. Estado actual de la arqueología en Aragón (Zaragoza 1987). I Ponencias: 97-131. Zaragoza.

Álvarez Gracia, A. y Bachiller, A. 1994-1996: "La evolución del urbanismo en el Bajo Aragón durante los periodos del Bronce FinalHierro Antiguo". Gala 3-5: 175-182.

Ambers, J.; Matthews, K. y Bowman, S. 1991: "British Museum Natural Radiocarbon measurements XXII". Radiocarbon 33 (1): 51-68. https://doi.org/10.1017/s0033822200013205

Antoñanzas, M. A. e Iguacel, P. 2011: "Edad de los Metales". En J. L. Cinca y R. González: Historia de Calahorra. Amigos de la Historia de Calahorra. Calahorra: 45-64

Aranda-Contamina, P.; Lorenzo, J. I. y Rodanés, J. M. 2016: "Estructuras de ocupación de la ladera sudoeste de El Morredón (Fréscano, Zaragoza)". En J. I. Lorenzo y J. M. Rodanés (eds.): Actas del I Congreso de Arqueología y Patrimonio Aragonés (Zaragoza 2015) I: 179-187. Zaragoza.

Aranda-Contamina, P. y Rodanés Vicente, J. M. 2016: "Historia de las investigaciones sobre el Bronce Final y Primera Edad del Hierro en Aragón. Una revisión crítica". En M. Ayarzagüena, G. Mora y J. Salas (eds.): 150 años de Historia de la Arqueología: teoría y método de una disciplina. Memorias de la Sociedad Española de Historia de la Arqueología III. Madrid: 263-282.

Armendáriz, J. 2008: De aldeas a ciudades: el poblamiento durante el primer milenio a. C. en Navarra. Gobierno de Navarra, Institución Príncipe de Viana. Pamplona.

Arnal, J. y Riquet R. 1961: "Origines de la Poterie Excisée dite de Saint-Vérédème". En Actes du Premier Colloque International d'Études Gauloises, Celtiques et Protoceltiques (Chateaumeillant, Cher 1960). Ogam Celticum 1: 15-24.

Barrios, I. 2004: El yacimiento de Cueva Lóbrega (Torrecilla de Cameros, La Rioja). Instituto de Estudios Riojanos. Logroño.

Bayliss, A. 2015: "Quality in Bayesian Chronological Models in Archaeology". World Archaeology 47 (4): 677-700. https://doi.org/10.1080/00438243.2015.1067640

Bayliss, A.; Bronk Ramsey, C.; Van der Plicht, J. y Whittle, A. 2007: "Bradshaw and Bayes: towards a timetable for the Neolithic". Cambridge Archaeological Journal 17 (1): 1-28 https://doi.org/10.1017/s0959774307000145

Beltrán, A. 1956: "El Bronce Final y la Edad del Hierro en el Bajo Aragón”. En M. Almagro, A. Beltrán y E. Ripoll (eds.): Prehistoria del Bajo Aragón. Instituto de Estudios Turolenses. Zaragoza: 109. 159.

Beltrán, A. 1960: "La indoeuropeización del Valle del Ebro". En Primer Simposium de Prehistoria Peninsular (Pamplona 1959): 103-124. Pamplona.

Blanco González, A. 2010: “¿Nuevos hogares para los emigrantes? Casas y paisajes en el debate sobre el límite entre Cogotas I y el Primer Hierro en el valle del Duero". Zephyrus LXVI: 155-179.

Blanco González, A. 2012: "Excisión, boquique y SIG. Hacia un enfoque territorial de Cogotas I". En J. A. Rodríguez Marcos y J. Fernández Manzano (eds.): Cogotas I. Una cultura de la Edad del Bronce en la Península Ibérica. Homenaje a M. ${ }^{a}$ Dolores FernándezPosse. Serie Arte y Arqueología 30, Universidad de Valladolid. Valladolid: 17-38.

Blanco González, A. 2015: “Emulación decorativa y cerámicas ancestrales. Posibles fuentes de inspiración de las alfareras meseteñas de la Edad del Bronce". Zephyrus LXXVI: 39-56. https://doi.org/10.14201/zephyrus2015763956

Blanco González, A. 2018: "Copying from sherds. Creativity in Bronce Age pottery in Central Iberia (1800-1150 BC)". En J. Sofaer (ed.): Considerin creativity. Creativity, knowledge and practice in Bronze Age Europe. Archaeopress Archaeology. Oxford: 19-38.

Blasco, C. 2012: "Cogotas I en la Meseta Española”. En J. A. Rodríguez Marcos y J. Fernández Manzano (eds.): Cogotas I. Una cultura de la Edad del Bronce en la Península Ibérica. Homenaje a M. ${ }^{a}$ Dolores Fernández-Posse. Serie Arte y Arqueología 30. Universidad de Valladolid. Valladolid: 187-219.

Bosch Gimpera, P. 1932: Etnologia de la península ibèrica. Ed. Alpha. Barcelona.

Bosch Gimpera, P. 1945: El poblamiento antiguo y la formación de los pueblos de España. Imprenta Universitaria. México.

Bowman, S.; Ambers, J. y Leese, M. 1990: "Re-evaluation of British Museum radiocarbon dates issued between 1980 and 1984". Radiocarbon 32 (1): 59-79. https://doi.org/10.1017/s0033822200039953

Bronk Ramsey, C. 1995: "Radiocarbon calibration and analysis of stratigraphy: the OxCal program". Radiocarbon 37 (2): 425-430. https://doi.org/10.1017/s0033822200030903

Bronk Ramsey, C. 2009: "Bayesian Analysis of radiocarbon dates". Radiocarbon 51 (1): 337-360. https://doi.org/10.1017/s0033822200033865

Bronk Ramsey, C. y Lee, S. 2013: "Recent and planned developments of the program OxCal". Radiocarbon 55 (2-3): 720-730. https://doi.org/10.1017/s0033822200057878

Buck, C. E. y Meson, B. 2015: "On being a good bayesian”. World Archaeology 47 (4):567-584. https://doi.org/10.1080/00438243.2015.1053977

Cabré, J. 1929: Excavaciones en el Roquizal del Rullo (Fabara). Zaragoza. Memorias de la Junta Superior de Excavaciones y Antigüedades 101. Madrid.

Cabré, J. 1930: Excavaciones de las Cogotas, Cardeñosa (Avila), I. El Castro. Memorias de la Junta Superior de Excavaciones y Antigüedades 110. Madrid.

Castiella, A. 1977: La Edad del Hierro en Navarra y Rioja. Excavaciones en Navarra 8. Pamplona.

Castiella, A. 1995: "En los albores de la historia. La Edad del Hierro". Cuadernos de Arqueología de la Universidad de Navarra 3: 185-230.

Castro-Martínez, P. V.; Mico, R. y Sanahuja, M. a E. 1995: "Genealogía y cronología de la "Cultura de Cogotas I" (El estilo cerámico y el grupo de Cogotas I en su contexto arqueológico)". Boletín del Seminario de Estudios de Arte y Arqueología LXI: 51-118.

Coffyn, A. 1979: "La céramique excisé dans l'ouest de la France. Sa diffusion en Espagne". En Actas del XV Congreso Nacional de Arqueología (Lugo 1977): 631-648. Zaragoza.

Dedet, B. 1980: "La ceramique excise du Premier Age du Fer en Languedoc oriental". Documents d'Archaeologíe Méridionale 3: 5-43.

Delibes, G. 1978: "Una inhumación triple de facies Cogotas I en San Román de la Hornija (Valladolid)". Trabajos de Prehistoria 35: 225 250.

Delibes, G. 1983: "Grupo cultural las Cogotas I: una visión crítica". Tribuna d'Arqueología: 85-92.

Delibes, G.; Fernández Manzano, J. y Rodríguez Marcos, J. A. 1990: "Cerámica de la plenitud de Cogotas I: el yacimiento de San Román de La Hornija”. Boletín del Seminario de Estudios de Arte y Arqueología 56: 64-105.

Delibes, G. y Fernández Miranda, M. 1986-1987: “Aproximación a la cronología del grupo de Cogotas I". En Coloquio internacional sobre la Edad del Hierro en la Meseta Norte (Salamanca 1984). Zephyrus XXXIX-XL: 17-30.

Delibes, G.; Romero, F. y Abarquero, F. J. 2000: “Cerámicas excisas de discutible filiación Cogotas I en el Bronce Tardío de la Península ibérica. Una taza de 'estilo Duffaits' procedente de la Cueva del Asno (Los Rábanos, Soria)". Soria arqueológica 2. Homenaje a Luis Argente Oliver: 97-130.

Delibes G.; Romero, F.; Sanz Mínguez, C.; Escudero Navarro, Z. y San Miguel Maté L. C. 1995: "Panorama arqueológico de la Edad del Hierro en el Duero Medio". En G. Delibes, F. Romero y A. Morales (eds.): Arqueología y medio ambiente. El primer milenio A.C. en el Duero Medio. Junta de Castilla y León. Valladolid: 49-146.

Fernández Posse, M. D. 1998: La investigación protohistórica en la Meseta y Galicia. Arqueología Prehistórica 1, Síntesis. Madrid.

Galilea, F. 2011: "Cronología de la prehistoria Alavesa según dataciones de C-14". Estudios de Arqueología Alavesa 26: 177-192.

García López, E. 1994: "Un modelo de análisis de evolución arquitectónica e interpretación social. El asentamiento del Bronce Final- 
Primera Edad del Hierro del Alto de la Cruz (Cortes, Navarra)". Pyrenae 25: 93-110.

Gómez de Soto, J. 1973: "La Grotte sepulcrale des Duffaits (La Rochette, Charente)". Bulletin de la Société Préhistorique Française 70 401-444. https://doi.org/10.3406/bspf.1973.4386

Gómez de Soto, J. 1995: Le Bronze moyen en Occident. La culture des Duffaits et la civilisation des Tumulus. L'Age du Bronze en France 5 Picard. Paris.

Gómez de Soto, J. 2010: "Les relations entre le groupe de Haguenau et la civilisation des Tumulus nord-alpins et les cultures du Bronze moyen de France occidentale. Quelle vision en 2006?". En A. Richard, P. Barral, A. Daubigney, G. Kaenel, C. Mordant y J. F. Piningre (eds.): L'isthme européen Rhin-Rhône-Saône dans la Protohistoire. Approches nouvelles en hommage à Jacques-Pierre Millotte, actes de la table ronde (Besançon 2006). Presses universitaires de Franche-Comté, Annales littéraires 860, série Environnement, sociétés et archéologie 13. Besançon: 255-264.

Gómez de Soto, J. 2013: "En France de l'Ouest, de la Loire à l'Aquitaine septentrionale, de la céramique cannelée au style RSFO. Diffusion ou polygénie?". En W. Leclercq y E. Warmenbol (eds.): Échanges de bons procédés. La céramique du Bronze final dans le nord-ouest de l'Europe (Bruxelles, Belgique 2010). Études d $\square$ archéologie (CReA-Patrimoine) 6. Bruxelles: 267-286.

Gómez de Soto, J.; Gruet, M. y Pautreau, J. P. 1988: "La période du Bronze final IIb-IIIa en Centre-Ouest”. En P. Brun y Cl. Mordant (eds.): Le Groupe Rhin-Suisse-France orientale et la notion de Civilisation des Champs d'Urnes. Actes du colloque (Nemours 1986). Mémoires du Musée préhistorique d'Ile de France 1, A.P.R.A.I.F. Nemours: $517-524$.

Hamilton, W. D. y Krus, A. M. 2017: "The myths and realities of Bayesian chronological modeling revealed". American Antiquity 82: 1-17. https://doi.org/10.1017/aaq.2017.57

Harrison, R.; Moreno, G. y Legge, A. J. 1994: Moncin: un poblado de la Edad del Bronce (Borja, Zaragoza). Diputación General de Aragón. Zaragoza.

Hernández Vera, J. A. 1983: "Difusión de elementos de la cultura de Cogotas hacia el Valle del Ebro. $1^{\text {er }}$ Coloquio sobre Historia de La Rioja”. Cuadernos de Investigación del Colegio Universitario de La Rioja IX: 65-89.

Jimeno, A. 1984: Los Tolmos de Caracena (Soria). Campañas de 1977, 1978 y 1979. Nuevas bases para el estudio de la Edad del Bronce en la zona del Alto Duero. Excavaciones Arqueológicas en España 134. Madrid.

Karlsberg, A. J. 2006: Flexible Bayesian methods for archaeological dating. Tesis Doctoral. Universidad de Sheffield. https://core.ac.uk/download/pdf/42605970.pdf [Consulta 20/02/2018]

Lee, S. y Bronk Ramsey, C. 2012: "Development and application of the trapezoidal model for archaeological chronologies". Radiocarbon 54 (1): 107-122. https://doi.org/10.1017/s0033822200046786

Llanos, A.; Armendáriz, J.; Castiella. A.; Peñalver, X.; Saenz, P. y Unzueta, M. 2009: "La Edad del Hierro en el Cantábrico Oriental y su entorno". En A. Llanos (ed.): Actas del Congreso Internacional Medio siglo de Arqueología en el Cantábrico Oriental y su entorno (Vitoria 2007): 201-344. Vitoria.

López Cachero, F. J. 2007: "Sociedad y economía durante el Bronce Final y la Primera Edad del Hierro en el Noreste Peninsular: una aproximación a partir de las evidencias arqueológicas". Trabajos de Prehistoria 64 (1): 99-120. https://doi.org/10.3989/tp.2007.v64.i1.96

Maluquer, J. 1954: El yacimiento halsttático de Cortes de Navarra. Estudio crítico I. Diputación Foral de Navarra, Institución Príncipe de Viana. Pamplona.

Maluquer, J. 1958: El yacimiento hallsttático de Cortes de Navarra. Estudio crítico II. Diputación Foral de Navarra, Institución Príncipe de Viana. Pamplona.

Maluquer, J.; Munilla, G. y Gracia Alonso, F. 1990: "Alto de la Cruz (Cortes, Navarra): campañas, 1986-1988". Trabajos de Arqueología Navarra 9: 11-245.

Martínez Santaolalla, J. 1946: Esquema paletnológico de la Península Hispánica. Madrid, $1^{\text {a }}$ ed.1941.
Maya, J. L. 1981: "La Edad del Bronce y la Primera Edad del Hierro en Huesca". Actas de la I Reunión de Prehistoria Aragonesa (Huesca 1981). Bolskan 7: 129-165.

Maya, J. L. 1992-1993: "El Bronce Final-Hierro Inicial en la zona norte del valle del Ebro". Segundos Encuentros de Prehistoria Aragonesa (Caspe, Zaragoza, 1986). Bajo Aragón Prehistoria IX-X: 7-50.

Maya, J. L. y Petit, M. A. 1986: "El grupo del nordeste. Un nuevo conjunto de cerámicas con boquique en la Península Ibérica". Anales de Prehistoria y Arqueología 2: 49-71.

Millote, J. P. 1961: "L'influence du groupe de Haguenau sur les civilisations protohistoriques d'Europe occidentale". Revue Archèologique de l'Ests et du Centre-Est, tome XII, Fasc. 3: 210-216.

Moreno, G. y Harrison, R. 1990: "Moncín: una secuencia cultural de la Edad del Bronce (Borja, Zaragoza)". Cuadernos de Estudios Borjanos 23-24: 11-28.

Molina, F. y Arteaga, O. 1976: "Problemática y diferenciación en grupos de la cerámica excisa en la Península Ibérica". Cuadernos de Prehistoria de la Universidad de Granada 1: 175-214.

Moral del Hoyo, S.; Rodríguez Marcos, J. A. y Diez Fernández de Lomana, J. C. 2003-2004: "La cerámica de la cueva de El Mirador (Ibeas de Juarros, Burgos) en el contexto del Bronce Medio de la Sub-Meseta Norte". Boletín del Seminario de Estudios de Arte y Arqueología 69-70: 57-74.

Mordant, C. 1989: "Transgressions culturelle et mouvements de populations aux XIV-XIII siècles avant notre ère dans le Bassin Parisien. Compétition culturelle et phènomène de lisière". En Dynamique du Bronce Moyen en Europe occidentale. Actes du 113 Congrès National des Sociètés Savantes (Strasbourg 1988). Paris, Editions des Travaux Historiques et Scientifiques: 283-304.

Narvarte, N. 2001: "Cogotas I en el Valle medio del Ebro: estado de la cuestión en la provincia de La Rioja". Berceo 140: 41-76.

Pascual González, H. 2000: "De la Edad de los Metales hasta Roma". En: La Rioja Tierra Abierta, Calahorra: 87-120.

Pascual Mayoral, P. y Pascual González, H. 1984: Carta Arqueológica de la Rioja: El Cidacos. Amigos de la Historia de Calahorra. Logroño.

Pellicer, M. 1984a: "La problemática del Bronce final-Hierro del nordeste hispano: elementos del sustrato". En F. J. Fortea Pérez (ed.): Scripta praehistorica, Francisco Jordá Oblata. Universidad de Salamanca. Salamanca: 399-430.

Pellicer, M. 1984b: "Elementos ultrapirenaicos y hallstattizantes en el horizonte del Bronce Final del Noreste hispano". Habis 15: 309-344.

Pellicer, M. 1985: "El problema de la cerámica excisa del Ebro". XVII Congreso Nacional de Arqueología (Logroño 1983): 347-356. Zaragoza.

Pérez Arrondo, C. 1983: "Estratigrafía arqueológica en Partelapeña (El Redal, La Rioja)". XVI Congreso Nacional de Arqueología (Murcia, Cartagena 1982): 439-441. Zaragoza.

Pérez de Barradas, J. 1934: "Notas prehistóricas II. La primera invasión celta en la meseta central española". Actas y Memorias de la Sociedad Española de Antropología, Etnografía y Prehistoria XIII.

Pettitt, P. y Zilhao, J. 2015: "Problematizing Bayesian approaches to prehistoric chronologies". World Archaeology 47 (4): 525-542. https://doi.org/10.1080/00438243.2015.1070082

Picazo, J. 1993: La Edad del Bronce en el Sur del Sistema Ibérico Turolense. I. Los materiales cerámicos. Monografías arqueológicas del Seminario de Arqueología y Etnología Turolense 7, Colegio Universitario de Teruel. Teruel.

Picazo, J. 2005: "El poblamiento en el Valle Medio del Ebro durante la Prehistoria Reciente: zonas y procesos". Revista d'arqueologia de Ponent 15: 97-118

Picazo, J. y Rodanés, J. M. (eds.) 2009: Los poblados del Bronce Final y Primera Edad del Hierro. Cabezo de la Cruz. La Muela. Gobierno de Aragón, Departamento de Educación, Cultura y Deporte. Zaragoza.

Piningre, J. F. y Plouin, S. 1989: "Documentation cartographique". En Actes du 113 Congrès National des Sociètés Savantes (Strasbourg 1988). Dynamique du Bronce Moyen en Europe occidentale. París: $552-579$.

Ramón, N. 2006: "La cerámica del Neolítico Antiguo en Aragón". Caesaraugusta 77 (número monográfico).

Trab. Prehist., 76, N. ${ }^{\circ}$ 1, enero-junio 2019, pp. 84-101, ISSN: 0082-5638

https://doi.org/10.3989/tp.2019.12227 
Rey, J. 1987: "La población prehistórica del interfluvio Flumen-Alcanadre". Bolskan 4: 67-122.

Rodanés, J. M. 1995: "El Bronce Medio y Tardío en La Rioja”. Cuadernos de Prehistoria y Arqueología 22: 37-82

Rodanés, J. M.; Gil Zubillaga, L. y Aranda-Contamina, P. 2016: Bronce Final y Primera Edad del Hierro en la Rioja. Excavación de los fondos de cabaña de El Sequero (Arrúbal, La Rioja). Trabajos del Museo de la Rioja 25. Logroño.

Rodanés, J. M. y Picazo, J.V. 2005: El proceso de implantación y desarrollo de las comunidades agrarias en el Valle Medio del Ebro. Monografías Arqueológicas 40, Prensas Universitarias. Zaragoza.

Rodanés, J. M. y Sopena, M. ${ }^{\text {a }}$ C. 1998: El Tozal de Macarullo (Estiche, Huesca): el Bronce Reciente en el Valle del Cinca. Centro de Estudios de Monzón y Cinca Medio. Monzón.

Rodríguez Marcos, J. A. 2007: Estudio secuencial de la Edad del Bronce en la Ribera del Duero (provincia de Valladolid). Arqueología en Castilla y León 7, Junta de Castilla y León. Valladolid,

Rodríguez Marcos, J. A. 2012: "Algunas notas acerca del proceso formativo de la cultura de Cogotas I". En J. A. Rodríguez Marcos y J. Fernández Manzano (eds.): Cogotas I. Una cultura de la Edad del Bronce en la Península Ibérica. Homenaje a M. ${ }^{a}$ Dolores FernándezPosse. Serie Arte y Arqueología 30, Universidad de Valladolid. Valladolid: 147-164.

Rodríguez Marcos, J. A. y Fernández Manzano, J. (eds.) 2012: Cogotas I. Una cultura de la Edad del Bronce en la Península Ibérica. Homenaje a $\mathrm{M}^{a}{ }^{a}$ Dolores Fernández-Posse. Serie Arte y Arqueología 30. Universidad de Valladolid. Valladolid.

Roudil, J. L. 1972: "Les techniques décoratives de la céramique - préhistorique du Languedoc Oriental". Bulletin de la Société Préhistorique Française 69 (1): 430- 443. https://doi.org/10.3406/bspf.1972.8176
Roussot- Larroque, J. y Merler J. C. 2012: "La céramique du Bronce Final en Aquitaine: elements de synthèse". Documents d'Archaeologie méridionale 35: 175-204.

Royo, J. I. 1984: "Hábitat y territorio durante la $1^{\text {a }}$ Edad del Hierro en el Valle de la Huecha. Zaragoza". Arqueología espacial 4: 65-95.

Royo, J. I. 2005: “Los poblados de ‘El Morredón’ y ‘El Solano’ (Fréscano, Zaragoza) y la cultura de los Campos de Urnas en el valle del río Huecha". Cuadernos de Estudios Borjanos 48: 17-178.

Ruiz Zapatero, G. 1980: "Las cerámicas excisas del Valle del Ebro y sus relaciones con el Suroeste de Francia". Oskitania 1: 37-64.

Ruiz Zapatero, G. 1981: “Cerámicas excisas de la Primera Edad del Hierro en Aragón”. Turiaso II: 11-32.

Ruiz Zapatero, G. 1995: "El substrato de la Celtiberia Citerior: el problema de las invasiones". En F. Burillo Mozota (ed.): Poblamiento celtibérico (III Simposio sobre los Celtíberos, Daroca), Institución Fernando el Católico. Zaragoza: 25-40.

Ruiz Zapatero, G. 2010: "El Bronce Final y la Primera Edad del Hierro del Valle del Ebro: aprendiendo treinta años después". Pyrenae 22-23: 93-97.

Samaniego, B.; Jimeno, A.; Fernández, J. J. y Gómez, J. A. 2001: Cueva Maja (Cabrejas del Pinar. Soria): Espacio y simbolismo en los inicios de la Edad del Bronce. Memorias. Arqueología en Castilla y León 10, Junta de Castilla y León. Valladolid.

Sesma, J; Bienes Calvo, J. J.; Erce, A.; Faro, J. A. y Ramos, M. 2009: "La cerámica de estilo Cogotas I y los ciclos culturales en las postrimerías de la Edad del Bronce en Navarra". Cuadernos de Arqueología de la Universidad de Navarra 17: 39-83.

Sesma, J. y García, M. L. 1994: "Ocupación desde el Bronce Antiguo a la Edad Media en las Bárdenas Reales de Navarra”. Cuadernos de Arqueología de la Universidad de Navarra 2: 89-218. 